\title{
The Effect of Quarantining Welfare on School Attendance in Indigenous Communities
}

\author{
Deborah A. Cobb-Clark \\ University of Sydney \\ Institute for the Study of Labor (IZA) \\ ARC Centre of Excellence for \\ Children and Families Over the Life Course \\ Stefanie Schurer \\ University of Sydney \\ Institute for the Study of Labor (IZA)
}

\author{
Nathan Kettlewell \\ University of Technology Sydney \\ Institute for the Study of Labor (IZA) \\ ARC Centre of Excellence for \\ Children and Families Over the Life Course \\ Sven Silburn \\ Menzies School of Health Research
}

April 19, 2021

\begin{abstract}
We identify the causal impact of quarantining welfare payments on Aboriginal children's school attendance by exploiting exogenous variation in its rollout across communities. We find that income quarantining reduced attendance by 4.7 percent on average in the first five months. Attendance eventually returned to its initial level, but never improved. The attendance penalty does not operate through changes in student enrollments, geographic mobility, or other policy initiatives. Instead, we demonstrate that financial disruption may be responsible for the temporary reduction in school attendance. Supplemental analysis suggests that the policy rollout may have increased family discord.
\end{abstract}

JEL Classification: D04; I28; I38.

Keywords: Income management, Restricted transfers, Welfare quarantining, Indigenous disadvantage, School attendance, Policy evaluation.

Acknowledgements: Deborah Cobb-Clark is a Professor in the School of Economics at the University of Sydney. Nathan Kettlewell is a research fellow in the Economics Discipline Group at the University of Technology Sydney. Stefanie Schurer is a Professor in the School of Economics at the University of Sydney. Sven Silburn is a Professor at the Menzies School of Health Research. The authors thank the following people for their valuable feedback on this research: Heather d'Antoine, Victoria Baranov, Nicholas Biddle, Gawaian Bodkin-Andrews, Robert Breunig, Julie Brimblecombe, David Cooper, Marco Francesconi, Matthew Gray, Olga Havnen, James J. Heckman, Hilary Hoynes, Matthew James, Liz Moore, Patrick Nolan, David Ribar and Jim Smith; participants of seminars at the University of California Santa Barbara, University of Chicago, University of Essex, University of Melbourne, Australian National University, University of 
Western Australia, University of Technology Sydney, University of Wollongong, Institute for Fiscal Studies; and participants of an organised session at the Inaugural Conference of the Asian and Australasian Society of Labour Economists (Dec 2017). We are also grateful to two anonymous referees whose feedback greatly improved this work. This study uses data from the Northern Territory (NT) Early Childhood Data Linkage Project, "Improving the developmental outcomes of NT children: A data linkage study to inform policy and practice across the health, education and family services sectors", which is funded through a Partnership Project between the National Health and Medical Research Council (NHMRC) and the NT Government. This study uses administrative data obtained from the NT Department of Education through this NHMRC Partnership Project. The analysis has followed the NHMRC Values and Ethics: Guidelines for Ethical Conduct in Aboriginal and Torres Strait Islander Health Research (2003) and the Australian Institute of Aboriginal and Torres Strait Islander Studies (AIATSIS) Guidelines for Ethical Research in Australian Indigenous Studies (2012) (Reciprocity, Respect, Equality, Responsibility, Survival and Protection, Spirit and Integrity). The researchers are bound by, and the research analysis complies with, the ethical standards outlined in the ethics agreement HREC Reference Number: 2016-2611 Project Title: Improving the developmental outcomes of Northern Territory children: A data linkage study to inform policy and practice in health, family services and education (Human Research Ethics Committee of the Northern Territory Department of Health and Menzies School of Health Research). The authors acknowledge funding from an Australian Research Council (ARC) Discovery Early Career Research Award DE140100463, an ARC Discovery Grant DP140102614, the Centre of Excellence for Children and Families over the Life Course (project number CE140100027), and a University of Sydney SOAR Fellowship (2017-2018). The Data are protected by a third party agreement. Data access for replication purposes can be obtained through the governance protocol of the Children and Youth Research Development Program (CYDRP), Menzies School of Health Research. Data access requests for replication purpose should be directed to Professor Steve Guthridge (steve.guthridge@ @enzies.edu.au). For any enquires contact Stefanie Schurer at stefanie.schurer@sydney.edu.au. 


\section{Introduction}

Indigenous people in Australia, Canada, New Zealand, and the United States face extensive social and economic hardship despite living in some of the world's wealthiest nations. Their communities have been shaped by unique cultural and political events; yet widespread disadvantage has been a nearly universal experience. Rates of suicide and disease-related mortality are substantially higher (e.g., Hunter \& Harvey, 2002; Bramley et al., 2004; Cooke et al., 2007; Clifford et al., 2013), while educational attainment and income levels are lower (e.g., Cooke et al., 2007). Drug and alcohol problems (e.g., Brady, 2000), family violence (Memmott et al., 2001; Al-Yaman et al., 2006) and child maltreatment (Cross et al., 2000; Stanley et al., 2003; Sinha et al., 2011) are more prevalent. In short, in "all four countries, Indigenous poverty has been not only deep and widespread but persistent, defying policy prescriptions" (Cornell, 2006, p. 2).

We analyze the impact of the 2007 introduction of income management into remote Aboriginal communities in the Northern Territory. ${ }^{1}$ Initiated by the Australian Commonwealth Government in an effort to reduce the behavioral causes of disadvantage, income management required 50 percent of welfare payments to be quarantined for expenditure on priority needs, effectively limiting the funds available for alcohol, tobacco, pornography, and gambling. The policy exclusively targeted Aboriginal communities was compulsory, and was rolled out without substantive community input. Income management was part of the Northern Territory Emergency Response, which was enacted in response to a highly publicized report documenting child maltreatment and family violence within these communities (Wild \& Anderson, 2007). Its goal was to "stem the flow of cash going towards substance abuse and gambling and ensure that funds meant to be for children's welfare are used for that purpose" (Brough, 2007b). 
Income management had a broad reach. It applied to virtually all social assistance benefits including child care benefits, family tax benefits, and old-age pensions, not just those welfare benefits directed towards low-income families. Given the high degree of welfare reliance in the affected communities, 75 percent of all adults in prescribed communities had been income managed at some point within the rollout period (September 2007-October 2008) and 55 percent were still on income management by the end of it (AIHW, 2010). ${ }^{2}$ As Australia's social security system specifically targets families with children, it is likely that all parents were affected.

Although the welfare of children took centre stage in the policy debate, we know very little about the consequences of restricting welfare payments for children. This study is the first to provide empirical evidence on the policy's impact on Aboriginal children's schooling outcomes. We focus on daily school attendance rates, which are a systematically recorded, high-frequency measure of community functionality. Boosting school attendance rates in the Northern Territory was not a formal policy goal, however it was an expected outcome. ${ }^{3}$ The hope was that by redirecting consumption towards children, income management would improve attendance.

We identify the causal impact of income management by exploiting exogenous variation from the staggered rollout of the policy across communities. Because the rollout was place-based, benefit recipients were automatically income managed if they had lived in a prescribed community at any point between the policy's legislation and the rollout date. Exemptions were rare. Daily attendance data and exact program implementation dates allow us to precisely time the introduction of income management. Our difference-in-difference estimates have a causal interpretation so long as the rollout of income management is unrelated to trends in school attendance rates. We demonstrate the plausibility of this identification assumption by: i) reviewing the administrative process underpinning the rollout; ii) examining the relationship between community characteristics 
and program rollout; and iii) using event study methods to assess trends in attendance patterns preand post-income management. The resulting evidence gives us confidence that our identification strategy is sound. We address any remaining unobserved heterogeneity by controlling for community-, day- and day-of-the-week- fixed effects, and allowing each policy commencement group to have its own season-specific time-trend.

We find no evidence that income management led to an increase in student attendance. Rather, the introduction of income management reduced school attendance by 3 percentage points (4.7 percent) on average in the first five months after which attendance rates eventually returned to their initial levels. The attendance penalty is similar for boys and girls, but is stronger for secondary school students. Interestingly, the drop in attendance is not confined to students with low school attachment. Students with an above median propensity to attend school experienced greater (both in absolute and relative terms) falls in attendance.

We explore four key mechanisms - concurrent policy initiatives, geographic mobility patterns, student enrollments, and financial disruption - through which income management may have reduced school attendance. The complex nature of the NTER makes it important to consider the potential for concurrent policy effects to confound our results. Moreover, Aboriginal families frequently leave their 'home' communities to travel to other remote communities for social and cultural reasons (Memmott et al., 2006), creating substantial attendance (and enrollment) churn as students enter and exit schools (Taylor \& Dunn, 2010). Income management may have changed families' incentives or ability to temporarily leave their communities. At the same time, many children in the study communities are not enrolled in school at all (Wilson, 2013). Finally, in light of the evidence that welfare policies can have unintended consequences (Bitler \& Karoly, 2015), we consider whether the policy caused disruption and increased family stress. 
We demonstrate that income management did not significantly affect student enrollments or mobility patterns into and out of Aboriginal communities. Thus, the drop in school attendance does not appear to be due to increased churning in student enrollments or transfers. Nor is it due to concurrent policy initiatives. Instead, income management appears to have resulted in financial disruption in the form of increased transactions costs (Yu et al., 2008; AIHW, 2010) and shortterm income shocks (Doyle et al., 2020). Our supplemental analysis suggests that family discord may have also increased. Both have the potential to disrupt school attendance.

Our research makes an important contribution to the international debate on ending Indigenous disadvantage. Unlike the case in Canada, New Zealand, or the United States, the Australian Government is unique in quarantining welfare as a key strategy in closing the gap in Indigenous outcomes. Income management has been controversial. Despite widespread dissatisfaction with the scheme (Yu et al., 2008), some Aboriginal Australians believe that income management has had benefits in improving people's diets, reducing excessive money demands from family members (“humbugging”), and increasing savings (Central Land Council, 2008; AIHW, 2010). Evidence based on sound policy evaluation methods has been lacking. Despite this, the Australian Government remains committed to income quarantining as a policy option, announcing in the October 2020 Budget that new income management trials will be funded on an ongoing basis.

\section{Income Management in the Northern Territory}

\section{A. Background}

Governed by its own local government in conjunction with the Commonwealth Government, the Northern Territory (NT) is vast, covering approximately one sixth of the Australian continent. More than half of its 246,000 residents live in the capital city of Darwin. Aboriginal Australians 
make up 25.5 percent of the NT's total population - 51.0 percent in remote areas - despite constituting only 2.8 percent of the Australian population overall (ABS, 2016).

Aboriginal kinship relationships are complex, dynamic, and not easily captured by notions of family based on physical living arrangements (see Lohoar et al., 2014; Martin, 2017; Walter, 2017, for reviews). People see themselves in relation to others in their local communities as well as in other remote areas, making it common for children and adults to move between households. Raising children is a collective responsibility; Aboriginal children are given a great deal of autonomy to develop their skills by exploring their environment under the watchful eyes of the community at large (Lohoar et al., 2014; Muir \& Bohr, 2014). Although parents have high educational aspirations for their children (Walter, 2017), school and community leaders have struggled to find ways to ensure that Aboriginal children can access "Western cultural capital" while at the same time nurturing their Aboriginal culture (McTaggart, 1991; Trudgett et al., 2017).

Poor school attendance has been a persistent policy challenge. Prior to income management, average attendance rates were around 65 percent in primary school and 50 percent in high school (He et al., 2018). Common reasons for authorized absence include health issues, transportation problems, family obligations (e.g. attending funerals), and a lack of food and clothing (Dreise et al., 2016). One in ten primary-school absences are unauthorized, while in high school this rate is one in four (Hancock et al., 2013). Unauthorized absences are often explained by educational disengagement, peer factors and family factors (e.g. violence) (Dreise et al., 2016).

\section{B. Policy Origin}

In 2006, the NT Government responded to media reports of child sexual abuse in Aboriginal communities by establishing an independent review board which finalized its report in April 2007 (Wild \& Anderson, 2007). While the NT Government was still considering its own response, the 
Commonwealth Government intervened with the Minister for Indigenous Affairs declaring that there was "clear evidence that the Northern Territory Government was not able to protect these [Aboriginal] children adequately" (Brough, 2007a, p. 10). The result was the announcement on June 21, 2007 of a significant set of reforms collectively known as the Northern Territory Emergency Response (NTER) which was enacted on July 17, 2007 less than one month later.

Income management was the cornerstone of the NTER. Fully, 65 percent of households in targeted communities were reliant on government benefits as their main source of income giving them incomes below the national poverty line. ${ }^{4}$ Income management changed the way welfare entitlements were paid out to these households. While 50 percent of benefits (see Table A1, Appendix) were paid in the usual way, the remaining 50 percent was retained by Centrelink ${ }^{5}$ in an individual account to be allocated to a combination of priority goods (i.e. goods other than alcohol, tobacco, gambling, and pornography). Initially, people accessed their income-managed funds in three ways. First, in remote areas, purchases could be made at a licensed community store which would deduct funds from people's income-management accounts at the point of sale. Second, people could obtain store cards (gift cards) from Centrelink which were redeemable at participating stores in larger towns. Third, people could organize a third-party deduction, e.g., to a utility company or a landlord. Unallocated funds were retained in welfare recipients' incomemanagement accounts. In late 2008, the Basics Card was introduced. Operating through Australia's EFTPOS system, it increased transactions flexibility by effectively eliminating the need for store cards. ${ }^{6}$

Expenditure data are not available for our sample period. However, the majority of the allocated Centrelink funds under income management were spent on food (64 percent), housing (9.1 percent), store cards (6.3 percent), and clothing and footwear (5.9 percent). Some funds were 
allocated to a school nutrition program (2.6 percent), and a small fraction to education (less than 1.7 percent). Once the Basics Card was introduced, almost 100 percent of the allocated funds went to food, housing, and household goods (AIHW, 2010).

\section{The Rollout of Income Management}

Income management began in September 2007 and was gradually rolled out over the next 13 months to 73 Aboriginal communities and town camps. ${ }^{7}$ Typically, the rollout happened simultaneously in geographic clusters of three to four communities. Figure 1 highlights the progressive coverage of income management across communities.

[Figure 1 about here.]

The rollout of income management was not strictly random; several conditions needed to be met before income management began, none of which related specifically to schools or children. The main criterion was that the community had at least one store meeting certain restrictions around financial practices (e.g., not engaging in monopoly pricing) and merchandise availability that could be licensed to participate in the scheme. Other requirements included that Centrelink staff were available to discuss income management and set up budget allocations; a government NTER administrator was in place for the community; arrangements were in place for deductions associated with utilities and rent; and there was a police presence in the community. Once introduced to a community, income management became compulsory. Exemptions were made only in special cases when a person could demonstrate that they were not a regular member of an incomemanaged community. By March 31, 2009, 15,125 people were subject to income management; only 649 exemptions (3.0 percent of those ever income managed) had been granted (AIHW, 2010). 
The validity of our empirical strategy relies on the assumption that the rollout of income management was independent of trends in school attendance. To demonstrate that this assumption holds, we first consider the spatial variation in the timing of income management (see Figure 2). Although some regional clusters adopted income management at a similar time, there is no obvious spatial pattern to the rollout itself.

[Figure 2 about here.]

Second, we test whether the timing of income management is related to community characteristics. ${ }^{8}$ The 2006 Australian Census provides complete measures of community-level characteristics for 55 of the 78 communities and data on population size and gender ratios for an additional nine communities. For the remaining 14 communities we have no data at all. ${ }^{9}$ Estimation results are reported in Table 1 for both the sub-sample with complete data (Column 1, $\mathrm{n}=55)$ and the larger sample with incomplete data (Column 2, n=64).

[Table 1 about here.]

With the exception of household size (significant at 10 percent), we find no statistically significant relationship between community-level characteristics and rollout timing. Our $\mathrm{R}^{2}$ is 0.090 in the limited sample and 0.077 in the larger sample. More than 90 percent of the variation in the timing of income management is unexplained by observed community-level characteristics. In comparison, Hoynes and Schanzenbach (2009) find that similar demographic characteristics explain 14 percent of the variation in the timing of Supplemental Nutrition Assistance Program (SNAP) benefits. We also examine whether the distribution of observable characteristics of communities differs systematically across the policy rollout. Following the intuition of Goodman- 
Bacon (2018), we show that overall, there is no clear pattern in the correspondence between community characteristics and policy commencement (see Figure A1).

\section{Conceptual Framework}

Income management falls within a category of policies best described as 'restricted welfare'. These policies include in-kind transfers, conditional cash transfers (CCTs), and income quarantining. Policy makers justify the restriction of welfare benefits by resorting to paternalism, especially when the consumption of certain goods has either negative (e.g., alcohol and tobacco) or positive (e.g., education and health care) externalities for families and children (Currie \& Gahvari, 2008). Overall, the literature on restricted welfare in developed countries suggests that, while some policies do seem to improve social and economic well-being (e.g., SNAP), many others fail to achieve their objectives. Their long-term impact and cost-effectiveness remain unclear (Gentilini, 2016).

\section{A. Intended Policy Consequences}

Income quarantining as a form of restricted welfare is unique to Australia. ${ }^{10} \mathrm{By}$ restricting welfare payments, the legislation aimed "to promote socially responsible behaviour, particularly in relation to the care and education of children". ${ }^{11}$ Informally, the aims of quarantining welfare payments also included an attempt to protect vulnerable family members - especially women - from financial exploitation and demands for money from relatives, a practice known as "humbugging" (see Howard, 2007). Thus, income management involves an element of female empowerment, which is associated with better outcomes for children (Duflo, 2012).

Figure 3 describes the intended effects of income management (Panel A). ${ }^{12}$ It depicts all possible consumption combinations of excluded goods ( $y$ axis) and priority goods ( $x$ axis), given 
a budget constraint. Households have different preferences for priority and excluded goods. In the absence of income management, households face a budget constraint of MN. Inframarginal households spend less than 50 percent of their budget on excluded goods (point B) while extramarginal households spend more than 50 percent on excluded goods (point A).

[Figure 3 about here.]

In restricting the allowable consumption bundles, income management does not shift the budget constraint. The money equivalent of benefit entitlements remains the same. Income management, however, introduces a kink in the budget constraint at point $\mathrm{C}$ (DCN). Once households reach their mandated spending limit for excluded goods (point C), further reductions in priority good spending can no longer legally be traded off against increased spending on excluded goods. Hence segment DC of the budget constraint is horizontal. Although along DC households are not fully expending their total benefit entitlements, these unspent funds cannot legally be used to purchase additional excluded goods due to the administrative constraints imposed by income management. If income management operates as intended, extramarginal households would be expected to reduce their spending on excluded goods to 50 percent of their total benefits (point $\mathrm{C}$ ). The consumption patterns of inframarginal households would be expected to be unchanged. Overall, by earmarking money for priority goods, income management is expected to increase such consumption.

\section{B. Unintended Policy Consequences}

Theoretically, income management could also have unintended consequences. The trade offs between priority and excluded goods depicted in panel A rest on the assumption that income 
management does not induce price, illicit behavioral, or priming effects. Each of these could in theory result in a reduction in the consumption of priority goods. First, the policy may have increased prices of priority goods, as licensed stores were given a de facto monopoly over selling priority items. This would tilt the budget constraint $(\mathrm{CN})$ inwards. Second, the mandated spending constraints on excluded goods are likely to increase the likelihood of underground markets emerging. Some extramarginal households may find that they can increase their utility by trading some priority goods for excluded goods in the underground market (e.g. trading food for alcohol). Panel B of Figure 3 depicts the implications of an underground market for households' consumption patterns. Households now face a budget constraint of FCN where the slope of NC is determined by the price of excluded goods in terms of priority goods in the underground market. The underground market allows extramarginal households to spend more than 50 percent of their benefits on excluded goods, though both the income and substitution effects push them to reduce their consumption of excluded goods once income management is introduced. Finally, by introducing a mental anchor, inframarginal households may be primed to reduce their consumption of priority goods closer to 50 percent of entitlements and increase the amount of excluded goods they consume.

\section{Consequences of the Policy on School Attendance}

Given this framework, we would expect an improvement in school attendance for extramarginal households, absent the unintended consequences discussed above. The international literature on school participation in poor communities suggests that lack of nutrition, health problems, and income poverty are the most common risk factors (Kremer \& Holla, 2009). Through income management, children would be better fed and healthier, and benefit from a greater share of household resources earmarked for school expenditures. Thus, we would expect school attendance 
to improve. Other anticipated social benefits (e.g. reduced humbugging) may also act to reduce barriers to attendance.

The policy could have reduced priority good consumption for extramarginal households if an underground market emerged and the income effects were larger than the substitution effects (e.g. because demand for excluded goods is highly inelastic). Anchoring bias or higher prices could have led to a similar effect, with negative effects on school attendance.

\section{Consumption Patterns}

Data limitations preclude any impact evaluation of income management on consumption and expenditure patterns in NT Aboriginal communities. There is, however, reason to believe that income management may not have resulted in a substantial shift in consumption. For instance, empirical evidence from localized studies is consistent with the view that income management had no impact on food purchases (Brimblecombe et al., 2010) and minor impacts on gambling behaviors (Lamb \& Young, 2011).

Similarly, Doyle et al. (2020) analyze 2003-04 Household Expenditure Survey (HES) data and find that - prior to income management - low income and welfare dependent households in the NT were already spending on average more than 60 percent of their income on priority goods such as food, rent and utilities. This suggests that many households were inframarginal and therefore not directly affected by the spending restrictions imposed by income management. Our own analysis of the micro-level HES data reveals that between 13 to 20 percent of similar households were likely extramarginal at the time, although this figure should be treated with caution since it includes an unknown number of households that were not in the targeted NT communities. ${ }^{13}$ Thus, income management may have been binding for a small proportion of the population. 
Finally, reports of benefit cards being traded for cash indicate that an underground market may have developed at some point after the introduction of income management (Bray et al., 2012; Marston et al., 2020). The scope for income management to alter consumption is reduced to the extent that households are inframarginal and/or have access to an underground market.

\title{
IV. Data
}

\begin{abstract}
A. Attendance Data
Our analysis is conducted with data from the Northern Territory Early Childhood Data Linkage Project, which is funded through a Partnership Project between the National Health and Medical Research Council (NHMRC) and the NT Government. In particular, we rely on daily attendance and enrollment records provided by the NT Department of Education, covering all students enrolled in the public school system born from 1994 onwards. ${ }^{14}$ The use of daily data is critical to our estimation strategy as it allows us to fully exploit variation in program timing, despite the policy being rolled out over a relatively short time frame.
\end{abstract}

The sample is restricted to the period 2006-2009 (inclusive). Since income management was first introduced in September 2007 and fully rolled out by October 2008, this window covers approximately 1.5 years before and after the implementation period. We restrict our analysis to this window because the NTER income management scheme was reformed in 2010 in such a way that is not amenable to evaluation with our data. Our observation window allows us to determine whether income management was effective in the short- to medium-term.

To construct an estimation sample, we used the income management rollout schedule published in AIHW (2010), which lists the exact day on which income management commenced in each community and linked this to the school attendance data. ${ }^{15}$ We also observe students' year level in 
our data. In the Northern Territory, schooling is compulsory from ages 6-17 (implying that most students are legally obligated to be in school until at least the end of 10th grade). Grade levels are segmented into primary (1-6), middle (7-9) and senior schools (10-12). An optional transition year is available before first grade. We restrict the sample to students enrolled in grades 1-12. Our final dataset is an unbalanced panel of 9,162 students attending 130 different schools. There are approximately 200 school days in each calendar year and altogether we have more than 3.5 million student-day observations.

\section{B. Student and Community Characteristics}

Statistics on attendance and geographic mobility for the students in our sample highlight three important stylized facts. First, school attendance is persistently low. Second, students are highly mobile. Third, the vast majority of students reside in very remote areas that are characterized by significant economic disadvantage. Specifically, the average attendance rate is only 63.7 (57.9) percent for primary (secondary) students living in income-managed communities over the sample period (see Table 2). In comparison, the attendance rate is 86 percent for the rest of the Northern Territory during the same period. Table 2 also highlights the significant degree of mobility within this population. Between 38.6 and 40.5 percent of primary students experience at least one move in each year. Mobility is even higher for secondary students. This reflects the high degree of mobility of Aboriginal people generally in the Northern Territory.

The majority of students in our sample are enrolled in primary school (years 1-6). This is in part because there are more compulsory year levels in primary education. It also reflects the fact that enrollment drops sharply with age in remote Aboriginal communities (He et al., 2018). The marked increase in secondary students over the period is driven by the cohort restrictions in the 
data - students born in or after 1994 are at most 12 years old in 2006 and are too young for middle school. By 2009 a much larger proportion of students have transitioned into secondary education.

[Table 2 about here.]

Finally, 93.3 percent of the schools in our sample are located in areas classified as 'very remote' by the Australian Bureau of Statistics (based on distance to urban centers). The remainder are classified as 'remote'. To put this in perspective, less than one percent of the 2006 Australian population resided in very remote areas (ABS, 2008). All schools in our sample, except one, qualify for remote area benefits offered by the NT Department of Education to attract teachers. More than 60 percent of schools qualify for the highest benefits.

A comparison of community characteristics highlights the economic and social disparities between remote Aboriginal communities and the rest of Australia (see Table 3). The children in our sample come from small, geographically disparate communities (see also Figure 2). The average median age is much lower in our sample than in the rest of Australia; there are also substantial disparities in terms of labor force participation, employment and income, and household size. Our descriptive statistics reveal considerable heterogeneity across communities, in particular in labor force participation and languages spoken at home. On average, only 17.2 percent of households in income-managed communities speak English exclusively at home. ${ }^{16}$

[Table 3 about here.] 


\section{Estimation Strategy}

\section{A. Event Study Analysis}

We begin by analyzing the effect of income management using an interrupted time series design (i.e. the classic 'event study' framework popular in finance). After collapsing data to the community level we estimate the following model:

$$
Y_{c t}=\alpha+\sum_{d=-365}^{365} \pi_{c} 1\left(\tilde{\tau}_{c t}=d\right)+\gamma_{c}+\epsilon_{c t}
$$

where $Y_{c t}$ is average whole-day school attendance in community $c$ on school-day $t$ and $\tilde{\tau}_{c t}$ is the "event date" which measures the number of days since the introduction of income management. For example, $\tilde{\tau}_{c t}=-1$ if income management will be rolled out tomorrow, $\tilde{\tau}_{c t}=0$ if it was rolled out today, and $\tilde{\tau}_{c t}=1$ if it was rolled out yesterday. We restrict our data to the one-year window on either side of the implementation date implying that all communities are equally represented and sufficient observations are retained to examine pre- and post-implementation trends. We do not have a strictly balanced panel as school holidays and weekends create gaps in the data such that for some $t$ only a subset of communities identify the coefficient. ${ }^{17}$ The vector $\gamma_{c}$ captures community fixed effects and $\epsilon_{c t}$ is a stochastic error term. The data are weighted by the number of students in each community for each day.

The purpose of the event study analysis is to evaluate the validity of our identification assumption through examination of the pattern in event-date coefficients (see Hoynes \& Schanzenbach, 2009). If the introduction of income management is unrelated to trends in school attendance, then we would expect to see no systematic trend prior to the introduction of income 
management. At the same time, a discontinuous change in attendance patterns that coincides with the introduction of income management is consistent with income management having a causal effect.

\section{B. Difference-in-Differences Estimation}

Our baseline specification relies on a difference-in-differences (DD) approach that uses communities that receive income management later as a control group for those receiving income management earlier. After collapsing data to the community level, the estimation equation is:

$$
Y_{c d t}=\alpha+\beta I M_{c d t}+\lambda G_{c d t}+\gamma_{c}+\delta_{d}+\tau_{t}+\epsilon_{c d t}
$$

where $Y_{c d t}$ measures average full-day attendance in community $c$, recorded on school-day $t$ and day of the week $d . I M_{c d t}$ is an indicator variable that equals one if income management had been rolled out in the community on that day, and equals zero otherwise. The model accounts for community $\left(\gamma_{c}\right)$, day-of-the-week $\left(\delta_{d}\right)$, and time (in days) $\left(\tau_{t}\right)$ fixed effects, as well as average grade level of students in the community $\left(G_{c d t}\right)$. The inclusion of day fixed effects controls for a nonparametric time trend in attendance. Finally, $\epsilon_{c d t}$ is a stochastic error term and the remaining variables are parameters to be estimated. Weights proportional to the number of students in each community for each day are used in all our regressions. Our main interest is in $\widehat{\beta}$ which captures the effect of income management on average school attendance.

Our review of the administrative process underlying the introduction of income management, along with the lack of an empirical relationship between community characteristics and the onset of income management, give us confidence that the rollout of income management is not related to attendance patterns (see Section II.C). Nevertheless, we relax our identification assumption by 
adopting a less-flexible parametric specification for our time fixed effects and allowing the time trend in attendance to vary at the policy commencement group level as follows:

$$
Y_{c n d t}=\alpha+\beta I M_{c n d t}+\gamma_{c}+\rho_{n}+\rho_{n} \phi_{s}+\lambda G_{c n d t}+\delta_{d}+t+\epsilon_{c n d t}
$$

which accounts for community-level fixed effects, fixed effects for the four school terms each year $\left(\rho_{n}\right)$, an interaction between the school term and commencement group $(s \in C)$ for income management $\left(\rho_{n} \phi_{s}\right)$, and a linear time trend $t .{ }^{18}$ Other variables are as defined in Eq. 2. This specification is particularly appealing since school terms coincide with seasons in the Northern Territory, allowing us to control for seasonal patterns in attendance at the commencement group level. In Eq. 3, both the level of and term-specific trends in attendance are allowed to vary across communities. In all models, standard errors are clustered by community.

\section{Results}

\section{A. Attendance}

To establish the validity of the maintained assumptions underpinning the DD method, we first present results obtained from estimation of the event study model. The estimation of Eq. 1 results in separate estimated coefficients for each of 717 different event days for which attendance is measured. These coefficients effectively capture daily changes in attendance levels in the lead up to and following the introduction of income management. In Figure 4, we plot these coefficients before and after the introduction of income management. To suppress the degree of noise inherent in the daily data we group these coefficients into bins of roughly one month. 
[Figure 4 about here.]

There is little evidence of any systematic trend in school attendance prior to the introduction of income management. At the same time, we observe a discontinuous drop in attendance that occurs precisely at the onset of income management. Attendance rebounds quickly, however, returning to baseline levels in about six to 12 months. These results support the validity of our identification strategy and point to an adverse effect of income management on attendance. ${ }^{19}$

We turn now to the results of our DD estimation (Eqs. 2 and 3), presenting four model specifications: Model 1 includes no control variables; Model 2 includes control variables (Eq. 2); Model 3 includes commencement group-specific quarterly trends (Eq. 3); and Model 4 adds a full set of interactions between i) commencement group fixed effects, ii) school-term fixed effects, and iii) a linear time trend. Because of its flexibility, we consider Model 4 to be our preferred specification. Finally, since our event study results point to a dynamic effect of income management on attendance - namely a short-run decrease and subsequent return to trend - we also estimate Models 1-4 allowing the treatment effect to vary with days elapsed since the onset of income management (less than 30 days ago, 30-59 days ago, 60-89 days ago, 90-119 days ago, 120-149 days ago and 150+ days ago). Results from models with an aggregate treatment effect are presented in Panel A of Table 4; estimates from models with dynamic treatment effects are presented in Panel B. ${ }^{20}$

[Table 4 about here.]

We find that income management reduced school attendance by 1.9 percentage points (ppts), an effect significant at the 10 percent level (Model 4 Panel A). As our data cover approximately 1.5 years after the introduction of income management, this can be interpreted as the estimated 
average treatment effect over the short- to medium-term. The result is remarkably stable across specifications. Interestingly, Model 1 results (no controls) are close to the DD results, implying that school fixed effects and time trends are not driving the policy effect.

To explore whether this estimate is driven by specific communities, we iteratively estimate Model 4 dropping each community from the sample in turn. Point estimates from this influence analysis range between -2.5 and -1.6 ppts and in all but three cases are statistically significant at the 10 percent level. We also re-estimate Model 4 with a treatment interaction for communities receiving income management earlier (up until 30 April 2008) rather than later (after 30 April 2008). The average treatment effect for early recipients is -1.2 ppts in comparison to -2.5 ppts for late recipients and their difference is statistically insignificant. Thus, the attendance penalty we find does not stem from the influence of particular communities or the relative timing of the reform.

Results in Panel B indicate that the average effect masks important dynamics in attendance behavior. The response in attendance follows a U-shaped pattern. In the immediate 30 days after income management, school attendance is estimated to fall by 2.2 ppts (Model 4). The decrease in attendance is greatest $60-89$ days after income management is introduced (4.1 ppts), while there is no statistical difference in attendance $150+$ days post income management (-0.6 ppts). The average effect in the first five months is 3.0 ppts. Average attendance pre-treatment is 63 percent. This implies a reduction in attendance of 4.7 percent relative to the pre-treatment mean. Taken together, our results indicate that income management caused a reduction in school attendance in the shortterm. In the medium-term, attendance recovered but not beyond the baseline trend.

In an effort to understand the potential for anticipation effects, we have also estimated models that include indicators which capture the pre-treatment trends in school attendance (see Figure 5). ${ }^{21}$ Communities experienced a median consultation period of 46 days before income management 
began (AIHW, 2010). Initially, there was a great deal of confusion about whether or not income management would be linked to school attendance and the perception that schools would be supplying enrollment and attendance data to Centrelink may have undermined community-school relations (Kroneman, 2007). Moreover, some commentators have argued that Aboriginal Australians use school participation as a means of exercising agency when confronted with punitive policy measures (Petray, 2013). Consistent with this, we find that in our preferred specification (Model 4) school attendance is slightly lower in the months preceding the rollout of income management (relative to January 2006 until 5 months before income management was introduced in the community). It drops even further once income management begins. Benchmarking post-treatment attendance against attendance 30-60 days before the commencement reduces our estimated treatment effect by approximately $1.0 \mathrm{ppt}$. However, it remains negative, and we continue to strongly reject that income management resulted in any improvement in attendance as intended.

[Figure 5 about here.]

Finally, to test robustness to concerns that treatment effect estimates from multi-period DD designs can have undesirable properties in the presence of heterogenous or time varying treatment effects (see e.g. Goodman-Bacon, 2018; de Chaisemartin \& D’Haultfœuille, 2020; Callaway \& Sant'Anna, 2020), we follow the approach in Deshpande and Li (2019). ${ }^{22}$. Their approach involves appending separate datasets for each commencement group. In each dataset, treated units are those commencing the policy at that period, and controls are those commencing after some future date. The standard DD model is then estimated (our Model 2) with additional controls for if observations are after the treatment date (or for each pre- and post-grouping in the case of an event study specification). In our case, we narrow the data to 150 days either side of policy commencement in 
each generated dataset and use units treated in more than 150 days as controls. Our estimates, in Appendix Figure A2, are presented as an event study graph comparable to Figure 5. Our results are robust to this exercise. We continue to estimate a U-shaped drop in attendance that disappears after approximately 5-months. ${ }^{23}$

To put our results in perspective, note that a 3 ppts reduction in the probability of attendance over the first five months translates to 2.5 additional absences over that period. Hancock et al. (2013) argue that 'every day counts' in the sense that there is a strictly decreasing relationship between attendance and academic achievement. Schurer et al. (2018) demonstrate that variation in test scores among Aboriginal children in remote NT communities is explained by variation in school attendance. On this basis, it is possible that income management may have had a modest negative affect on academic achievement.

\section{B. Heterogeneity by Gender, School Level, and School Attachment}

Income management may have affected boys and girls differently. Aboriginal boys are at an educational disadvantage relative to Aboriginal girls from an early age (see Yap \& Biddle, 2010; Wilson, 2013; Biddle \& Meehl, 2016; He et al., 2018; Su et al., 2018). They are less likely to be attending school regularly and have lower test scores and attainment than Aboriginal girls. In our sample, the attendance rate for girls is 64.1 percent and 61.3 percent for boys. Biddle and Meehl (2016) argue that differences in the way that men and women experience discrimination, high incarceration rates among Aboriginal men, and the near absence of job opportunities for uneducated Aboriginal women all contribute to the gender gap in educational outcomes for Aboriginal children.

Moreover, educational disparities are much starker among high school students, particularly in remote Aboriginal communities (Herbert et al., 2014). School attendance rates drop steeply from 
fifth grade onwards; by tenth grade, the attendance rate in very remote areas is only 40 percent (He et al., 2018). A 2003 review of secondary education in the Northern Territory pointed to the large number of Aboriginal adolescents in remote areas not participating in education at all, noting that "the review team doubts that what is being delivered meets acceptable criteria for secondary education" (Ramsey, 2003, p. 164). A decade later, a subsequent review recommended that secondary education in remote and very remote schools be progressively relocated to urban areas with students accommodated in residential facilities (Wilson, 2013). It is therefore also crucial to understand whether the policy primarily affected students who were already at the brink of disengaging with the formal education system (Prout, 2008).

We investigate whether income management has heterogeneous effects on school attendance by estimating our preferred specification (Model 4) separately for: (i) boys versus girls; ii) primary (years 1-6) versus secondary (years 7-12) students; and (iii) students with low versus high propensities to attend school. It is important to note that because we only observe students born in 1994 or later, the results for secondary schools are largely driven by students in lower grade levels. Results are reported in Table 5.

[Table 5 about here.]

We find that the average attendance response to income management is slightly larger for boys (-2.1 ppts) than for girls (-1.8 ppts), but the difference is not statistically significant. The attendance response to the timing of income management is also similar for boys and girls. In both cases, the impact of income management on attendance follows a U-shaped pattern; attendance first falls, then rebounds and after 150 days becomes statistically indistinguishable from its initial level. For both boys and girls, the largest downturn in attendance occurs between 60-89 days after the 
introduction of income management, although the drop is deeper for boys ( 5 ppts) than girls (3.2 ppts). There is more evidence of heterogeneity across school level, with income management having a much larger average effect on the attendance of secondary school students in both absolute and relative terms ( -5.4 percent versus -2.0 percent).

We also explore how our estimates vary by students' long-term attachment to the school. Specifically, we re-estimate our models separately for students with high (above median) and low (below median) attendance propensities. ${ }^{24}$ The average treatment effect is -2.9 ppts $(-3.7$ percent) for students with high attendance propensities, while it is only -0.7 ppts ( -1.4 percent) for students with a low propensity to attend school. Despite the disparity in average treatment effects, the shortterm attendance response to the introduction of income management is very similar across the two groups. Both groups experience a large, statistically significant drop in attendance in the first month after the introduction of income management. Attendance continues to drop up until four months following income management. Only the longer run response depends on attendance propensity. Students with a high attendance propensity do not return to their longer-term school attendance rates even after five months (-3.2 ppts). Thus, income management affected all students in the short run and had a lasting effect on students with relatively strong school attachment.

\section{Potential Mechanisms}

Policy makers hoped that income management would redirect household spending away from goods and services that can cause social harm and towards goods and services that are good for child welfare. The belief was that this would increase school engagement by improving children's health and safety, increasing parents' attentiveness, and reducing financial harassment. 
Our results, however, indicate that income management reduced attendance in the short-term. In what follows, we investigate the potential mechanisms underlying this result. Specifically, we consider the extent to which our results reflect: i) the introduction of the NTER more broadly; ii) changes in student enrollments; iii) changes in student mobility; and iv) financial disruption. Overall, we find no support for the first three of these explanations. However, we do find evidence that financial disruption stemming from the reform may have been responsible for the temporary downturn in school attendance following the introduction of income management.

\section{A. Other NTER Measures}

Income management was introduced into a fluid and rapidly changing policy environment. Many other programs, including store licensing, child health checks, additional police support and various infrastructure projects, were also rolled out to Aboriginal communities as part of the NTER (see Table A1). One possibility is that, rather than identifying the effects of income management per se, our results instead capture the effects of one or more of these other programs. However, we think this is unlikely for two reasons.

First, the introduction of other NTER measures did not coincide with the rollout of income management. We document the cumulative coverage of the other key NTER measures across communities over the period July 2007 to July 2008 in Table 6. Alcohol restrictions were commonplace in remote communities even before 2007. The NTER introduced additional bans on alcohol and pornography that became effective almost immediately. ${ }^{25}$ These bans were in place in 88 percent of communities before income management began. In contrast, extra police and related measures were introduced into only 17 out of 78 communities during the rollout period. Amongst all other NTER measures, the school nutrition program seems to have the time-line that is most 
similar to that of income management. However, it is difficult to envisage how this would have reduced attendance. Rather, it provided an incentive for children to attend school. ${ }^{26}$

While the rollout schedule of the additional NTER components in Table 6 are not available, we know from policy documents which communities ultimately received a police station (18) or had their community economic development program (CEDP) removed (34). Excluding these communities makes our negative treatment effects stronger (see Tables A4 and A5).

[Table 6 about here.]

Second, our event study analysis indicates that our results are capturing the effects of income management rather than other components of the NTER. The decrease in school attendance occurs precisely at the point when income management is introduced into each community (see Figure 4).

Given that the introduction of other key NTER measures did not coincide with the rollout of income management, they do not provide a compelling explanation for this result. Moreover, any aggregate response to the NTER overall is captured by time fixed-effects.

\section{B. Enrollment}

Although school enrollment is mandatory until age 17 in the Northern Territory, in practice many children living in the remote Aboriginal communities are not enrolled in school (Wilson, 2013). In this section we explore whether the reduction in school attendance that occurred after the introduction of income management can be linked to changes in school enrollment. To the extent that income management led to safer, healthier, and more stable environments for children, it may also have had a beneficial effect in raising school enrollment rates. At the same time, enrollment rates may have also increased as a result of the initial uncertainty about whether income 
management would or would not be linked to children's lack of school participation. Some families may have moved to enroll children in school in the expectation that they would lose their benefits if their children were not attending school. In this case, the decline in attendance that we observe post income management might be due to a negative selection effect. That is, income management may have encouraged children with lower school attendance propensities to enroll.

We observe the total number of students enrolled in school in each community on each day. ${ }^{27}$ If income management influenced enrollment decisions, then we should see an increase in student numbers following its introduction. To investigate this, we re-estimate our event study model (Eq. 1) focusing on the number of enrolled students in community $c$ at time $t$. As before, we obtain estimates of our event-time indicators which identify deviations in the number of enrolled students relative to the omitted period $\left(\tilde{\tau}_{c t}=-365\right)$ and plot these against the onset of income management.

[Figure 6 about here.]

Figure 6 shows that enrollment appears to be increasing with time However, this is partly because our data only capture students born in 1994 or later. By 2009, these students are still yet to age out of the education system, which means that students entering grade 1 each year are not offset by students exiting secondary education. ${ }^{28}$ The slope of the trend in Figure 6 should therefore be interpreted with caution. What is important for our analysis is whether there is a systematic discontinuous change in enrollments that coincides with the onset of income management. There is no evidence of such an effect, making it unlikely that changes in school enrollments explain the estimated reduction in attendance. We reach the same conclusion when we estimate our DD models on the total number of students in the community (see Table A8). 


\section{Geographic Mobility}

Geographic mobility is high in NT Aboriginal communities - families frequently relocate for social and cultural reasons, including ceremonies and the maintenance of kinship (Memmott et al., 2006). Income management may have reduced geographic mobility. Travelling was made more difficult because benefit recipients had to plan ahead to arrange with Centrelink to have their income managed funds made available to stores outside their community (AIHW, 2010). ${ }^{29}$

If the onset of income management altered mobility patterns, our results could again be reflecting a selectivity effect as children with higher attendance rates disproportionately leave Aboriginal communities (or children with lower attendance rates disproportionately stay). We explore the pattern in geographic mobility using data from the entire Northern Territory. Schools are categorized by whether they are located in income-managed communities or not. Geographic mobility is measured by identifying students who change schools across communities allowing us to focus on the dynamics of in- and out-migration in income-managed communities. In-migration is defined as the number of students joining community $c$ on day $t$; this includes students moving from other income-managed communities; other non income-managed communities; or from outside our administrative dataset (e.g., interstate moves or moves between the private and public education sectors). Out-migration is defined as the reverse of in-migration.

The most common type of move is from one income-managed community to another (56.2 percent of moves within the Northern Territory in 2008). Moves i) from income-managed to non income-managed communities and ii) from non income-managed to income-managed communities account for an approximately even share of the remaining 43.8 percent of moves within the Northern Territory. Finally, of the 6,665 students enrolled in schools in income- 
managed communities in 2008 approximately 17.5 percent either entered or exited our administrative data system. Further details on mobility patterns are presented in Table A6.

Our approach to analyzing the mobility data is similar to that used for studying enrollments, using the event study models described in Eq. 1. In Figure 7 we plot the relationship between time since the onset of income management and the rate of in-migration (left) and out-migration (right). The $\mathrm{Y}$-axis is the deviation in the relevant mobility rate with $\tilde{\tau}_{s t}=-365$ set as the reference period. Focusing first on in-migration, we find no clear pattern in the data and certainly no evidence that mobility changes around the onset of income management. There is some indication of a small increase in the rate of out-migration around the time income management commenced. However, there is also considerable variability in the data and this result is not significant. Overall, Figure 7 does not provide strong evidence that student mobility was affected by income management. We also find no evidence of mobility changes in DD estimation results (Tables A9 and A10).

[Figure 7 about here.]

Although overall mobility into and out of income-managed communities seems to be unaffected by the introduction of income management, it is possible that the composition of the migration flow was affected. Specifically, in- and out-migrants may have become more or less selected with respect to their propensity to attend school. We address this issue by focusing our attention on students who did not move between 2006 and 2009 (41.9 percent). We estimate our main models using this sub-sample of students. Despite the smaller sample size, we find the same substantive results; there is a short-run reduction in attendance of up to 3.1 ppts (90-119 days) and no effect on attendance after 150 days (Table A7). We conclude that changes in mobility patterns are unlikely to explain the drop in school attendance as income management was introduced. 


\section{Financial Disruption and Family Functioning}

It is possible that the poor implementation and complex procedural rules of the income management policy, coupled with widespread community dissatisfaction, reduced family engagement with schools. In particular, the introduction of income management was characterized by a lack of consultation with stakeholders, confusion about how the policy would operate, hurdles in accessing welfare benefits, and difficulty checking account balances. Initially, Centrelink struggled to administer the new, individual income management accounts. As a consequence, it had to extend its operating hours to meet the increased service demand (FAHCSIA, 2008).

Some income-managed clients experienced short-term income disruptions because their welfare payments had been quarantined without their knowledge. At the end of November 2007, 22.6 percent of Centrelink clients were placed on "auto income management", because they had failed to contact Centrelink staff to allocate their funds (AIHW, 2010, p. 23). This lack of consultation with Centrelink staff resulted in a high point of unallocated funds in the magnitude of 50.3 percent on 23 November 2007 (AIHW, 2010, p. 30). In some cases, the disruption caused by expected but missing payments resulted in children being absent from school as they travelled with their parents to Centrelink offices in regional centers to sort out their benefits. ${ }^{30}$

The procedural rules associated with income management have also resulted in benefit payment suspensions (Doyle et al., 2020). Suspensions occurred if a recipient remained on auto income management for 13 weeks or more, made procedural errors, or was detained in jail. The number of affected community members was large. Nearly one in ten of all 21,763 incomemanaged clients had at least one payment suspended for reasons directly related to administrative rules governing access to benefits (AIHW, 2010, pp. 26-27). Doyle et al. (2020) calculate that during the roll-out of income management as much as AU $\$ 2,067,660$ in benefits may have been 
suspended. Although many suspended payments were restored by the end of the roll-out period, one third of suspensions continued beyond March 2009. These shortfalls in the benefit entitlement would have implied a severe temporary income shock for many households. ${ }^{31}$

The introduction of the Basics Card in 2008 was meant to improve outcomes by facilitating access to quarantined benefits. The Basics Card can be used to purchase goods and services in the same way as a regular debit card. This eliminated the need for priority goods to be purchased from either nominated community stores or using store cards previously obtained from Centrelink. The Basics Card significantly reduced the transaction costs associated with income management, particularly when travelling outside home communities. It may have also assisted in restoring social capital by allowing family members to pool resources. Although Basics Cards were protected by a personalized identification number (PIN), and clients were told not to share their card or PIN, in practice many people admit to doing both (AIHW, 2010; Bray et al., 2014). Qualitative evidence suggests that people viewed the Basics Card as a substantial improvement in the way income management operated (AIHW, 2010). This suggests that transactions costs may also have contributed to the financial disruption that people experienced as a result of the policy. ${ }^{32}$

Compounding any financial disruption was also the widespread dissatisfaction with the compulsory nature of the policy. Many felt that they were being unfairly targeted and did not need to be income managed (Yu et al., 2008; AIHW, 2010). Income management also placed constraints on resource sharing within families, which policy makers hoped would reduce the pressure ("humbugging") on women and the elderly to share their benefits with extended family members (AIHW, 2010). This aspect of the policy was poorly received, as remote Aboriginal communities are highly collectivist and resource sharing is an important social institution. 
Overall, it is plausible that the uncertainty and financial stress associated with the way that income management was rolled out reduced family functioning, increasing school absences. The short-term disruption to families' ability to make purchases and pay the bills while they worked to gain access to their Centrelink benefits would certainly have intensified the disadvantage they were already experiencing. Some women reported, for example, that income management led to more petty crime because of cash shortages (Equality Rights Alliance, 2011). Moreover, being preoccupied with pressing budgetary concerns leaves fewer cognitive resources available for decision making (Mani et al., 2013), including in relation to children (Cobb-Clark et al., 2019). In effect, "scarcity changes how people allocate attention: It leads them to engage more deeply in some problems while neglecting others" (Shah et al., 2012, p. 682). Adults' preoccupation with the temporary financial stress caused by the initial introduction of income management is likely to have had particularly profound effects for Aboriginal children who live in complex, fluid, extended families and have a great deal of agency over their own decisions. ${ }^{33}$

We investigate the link between the potential financial disruption of the income management policy and family functioning by conducting a supplemental analysis of data from the Longitudinal Study of Indigenous Children (LSIC). LSIC surveys Aboriginal children and their parents across Australia. LSIC allows us to explore the outcomes of a small number of families $(\mathrm{N}=30)$ who enter income management between 2008 and 2009 using a triple difference (DDD) methodology (see Appendix B for full details on methodology, data, and variable definitions). ${ }^{34} \mathrm{We}$ consider the following four outcomes: (1) harassment for money ("humbugging"); (2) alcohol consumption; (3) children exposed to arguing; and (4) money concerns. Results are presented in Table 7.

We find that income management increased the risks of humbugging by 29 ppts (116 percent relative to the mean) and of children being involved in or upset by family arguments by 20 ppts 
(95 percent). Income management is also associated with increased worry over money although this effect is estimated imprecisely. At the same time, there is no evidence that income management changed alcohol consumption - a key objective of the policy. This finding is consistent with other evidence that income management did not change sales in community stores (Brimblecombe et al., 2010) or the smoking and drinking behaviors of pregnant women (Doyle et al., 2020). When taken together, these results suggest that income management did not alter consumption patterns as intended, but instead increased financial stress and reduced family functioning.

[Table 7 about here.]

\section{Conclusion}

Relative to Canada, New Zealand, or the United States, Australia stands out for its use of welfare quarantining as a key strategy intended to enhance the well-being of Indigenous communities. Income management - similar to other forms of conditional cash transfers - aims to improve welfare by creating a healthy consumption environment. Currently, the Australian Government is actively extending its income management policy beyond Aboriginal communities. A new program has been rolled out universally in the Northern Territory, and several place-based programs are being trialled in other states to address entrenched disadvantage and high-risk consumption patterns. In some cases, income management is voluntary; in others it is compulsory.

While conditional cash transfer programs have been subjected to rigorous evaluation, there is little credible evidence regarding the impact of income management. We provide the first causal evidence linking income management to a key policy target - school attendance. In contrast to the policy's objectives, we find no evidence that school attendance increased after the introduction of 
income management. In fact, we estimate that attendance fell by 3 percentage points, or 4.7 percent, on average in the first five months after the introduction of income management. This drop in attendance does not appear to be due to other policy initiatives or to changes in either geographic mobility or school enrollment patterns. Rather, we argue that the administrative rules governing access to benefit payments have resulted in income insecurity, an unintended consequence of the policy. Combined, the policy's side effects appear to have led to increased family stress. Our findings echo those of Gennetian et al. (2016), who find that students receiving food stamps have disproportionately more behavioral problems at the end of the month when they are most likely to be subject to food insecurity.

Of course, the failure of income management to improve student attendance does not necessarily rule out other positive social and economic outcomes. If income management did meet other key objectives (e.g., lower substance abuse), however, then it is puzzling that we do not observe any improvement in school attendance over the study period given the likely link between these outcomes and school engagement. More broadly, the overall trend in school attendance between 2006 and today (He et al., 2018) suggests that the NTER and the many policies that followed failed to lift attendance rates in remote Aboriginal communities.

Taking a broader perspective, a key take-away message of our research is that program implementation matters. Consistent with Cameron and Shah (2014), our results suggest that policy makers should pay careful attention to the erosion of social capital when implementing new programs. This is particularly true in Aboriginal communities where attempts to reduce disadvantage through increased social mobility may put social and cultural capital at risk (Walter, 2015). Income management also provides an interesting case study for understanding how weak program fidelity may not only undermine the benefits to social welfare reform, but may also have 
harmful consequences. Of particular concern is the potential for these harmful effects to disproportionately affect vulnerable groups. In particular, we find that the school attendance penalty was larger for secondary school students who already have disproportionately low attendance rates (He et al., 2018). At the same time, we find that income management affected not only vulnerable groups, but also had a lingering effect on those students with a relatively high propensity to attend school regularly. Hence, income management may have undermined the efforts of Aboriginal families who were ensuring that their children attended school more regularly.

A key question for policy makers and researchers is whether restricted welfare policies, such as income management, are preferable to cash transfers. The few studies which compare the relative performance of cash versus in-kind transfers, usually in the context of food consumption and nutrition, find little evidence that one mode of delivery is superior to the other (Gentilini, 2016). At the same time, non-cash transfers are often associated with high administrative costs. The cost of administering income management was \$451 million (AUD) between the 2007-08 and 2009-10 financial years, or approximately $\$ 20,700$ per income-managed person. ${ }^{35}$ Further research is needed to understand whether or not this cost is offset by other social benefits beyond increased school attendance or whether - as some experts have argued (Altman, 2016) - these resources could be redeployed more productively to enhance the wellbeing of Indigenous Australians. 
References

ABS. 2008. Australian Social Trends 2008: Population Distribution. Australian Bureau of Statistics: Canberra.

ABS. 2016. Australian Census. Australian Bureau of Statistics. Retrieved from http://stat.abs.gov.au/itt/r.jsp?databyregion \\&ref=CTA2 (Viewed 30 November 2017)

AIHW. 2010. Evaluation of Income Management in the Northern Territory. Australian Institute of Health and Welfare: Occasional Paper No. 34.

Altman, Jon. 2016. "Blind-sided by Basics: Three Perspectives on Income Management in an Aboriginal Community in the Northern Territory." Australian Journal of Social Issues 51(4): 487-502.

Al-Yaman, Fadwa, Mieke Van Doeland and Michelle Wallis. 2006. Family Violence Among Aboriginal and Torres Strait Islander Peoples. Australian Institute of Health and Welfare Canberra: AIHW cat. no. IHW 17.

Bailey, Martha J. 2012. "Reexamining the Impact of Family Planning Programs on US Fertility: Evidence from the War on Poverty and the Early Years of Title X." American Economic Journal: Applied Economics 4(2): 62-97.

Bailey, Martha J. and Andrew Goodman-Bacon. 2015. "The War on Poverty's Experiment in Public Medicine: Community Health Centers and the Mortality of Older Americans." American Economic Review 105(3): 1067-1104.

Biddle, Nicholas and Meehl, Anneke. 2016. The Gendered Nature of Indigenous Education Participation and Attainment. Centre for Aboriginal Economic Policy Research, Working Paper No. 106/2016.

Bitler, Marianne P. and Lynn A. Karoly. 2015. "Intended and Unintended Effects of the War on Poverty: What Research Tells Us and Implications for Policy.” Journal of Policy Analysis and Management 34(3): 639-696.

Brady, Maggie. 2000. "Alcohol Policy Issues for Indigenous People in the United States, Canada, Australia and New Zealand.” Contemporary Drug Problems 27(3): 435-509.

Bramley, Dale, Paul Hebert, Rod T. Jackson and Mark Chassin. 2004. "Indigenous Disparities in Disease-specific Mortality, a Cross-country Comparison: New Zealand, Australia, Canada, and the United States.” The New Zealand Medical Journal 117(1207): 1-16.

Bray, J. Rob, Matthew Gray, Kelly Hand, Bruce Bradbury, Christine Eastman and Ilan Katz. 2012. Evaluating New Income Management in the Northern Territory: First Evaluation Report. Social Policy Research Centre.

Bray, J. Rob, Matthew Gray, Kelly Hand and Ilan Katz. 2014. Evaluating New Income Management in the Northern Territory: Final Evaluation Report. Social Policy Research Centre.

Brimblecombe, Julie K., Joseph McDonnell, Adam Barnes, Joanne Garnggulkpuy Dhurrkay, David P. Thomas and Ross S. Bailie. 2010. "Impact of Income Management on Store Sales in the Northern Territory." Medical Journal of Australia 192(10): 549-554. 
Brough, Malcolm. 2007a. Northern Territory National Emergency Response Bill 2007: Second Reading Speech. Commonwealth of Australia: House of Representatives.

Brough, Malcolm. 2007b. Social Security and Other Legislation Amendment (Welfare Payment Reform) Bill 2007: Second Reading. Commonwealth of Australia: House of Representatives. Buckmaster, Luke, Carol Eye and Michael Klapdor. 2012. Income Management: An Overview. Department of Parliamentary Services: Parliamentary Library Information Analysis Advice. Callaway, Brantly and Pedro H. C. Sant'Anna. 2020. "Difference-in-Differences with Multiple Time Periods." Journal of Econometrics. Forthcoming.

Cameron, Lisa and Manisha Shah. 2014. "Can Mistargeting Destroy Social Capital and Stimulate Crime? Evidence From a Cash Transfer Program in Indonesia." Economic Development and Cultural Change 62(2): 381-415.

Central Land Council. 2008. Reviewing the Northern Territory Emergency Response: Perspectives from Six Communities. Central Land Council.

Clifford, Anton C., Christopher M. Doran and Komla Tsey. 2013. "A Systematic Review of Suicide Prevention Interventions Targeting Indigenous Peoples in Australia, United States, Canada and New Zealand.” BMC Public Health 13(1): 1-11.

Cobb-Clark, Deborah Ann, Nicolas Salamanca and Anna Zhu. 2019. "Parenting Style as an Investment in Human Development.” Journal of Population Economics 32(4): 1315-1352.

Cooke, Martin, Francis Mitrou, David Lawrence, Eric Guimond and Dan Beavon. 2007. Indigenous Well-being in Four Countries: An Application of the UNDP'S Human Development Index to Indigenous Peoples in Australia, Canada, New Zealand, and the United States." BMC International Health and Human Rights 7(1): 1-11.

Cornell, Stephen. 2006. Indigenous Peoples, Poverty and Self-determination in Australia, New Zealand, Canada and the United States. Native Nations Institute for Leadership, Management, and Policy: JOPNA No. 2006-02.

Cross, Terry A., Kathleen A. Earle and David Simmons. 2000. "Child Abuse and Neglect in Indian Country: Policy Issues." Families in Society: The Journal of Contemporary Human Services 81(1): 49-58.

Currie, Janet and Firouz Gahvari. 2008. "Transfers in Cash and In-Kind: Theory Meets the Data. ” Journal of Economic Literature 46(2): 333-383.

de Chaisemartin, Clement and Xavier D'Haultfœuille. 2020. “Two-way Fixed Effects Estimators with Heterogeneous Treatment Effects.” American Economic Review 110(9): 2964-2996.

Deshpande, Manasi and Yue Li. 2019. "Who is Screened Out? Application Costs and the Targeting of Disability Programs." American Economic Journal: Economic Policy 11(4): 213-248.

Doyle, Mary-Alice, Stefanie Schurer and Sven Silburn. 2020. Unintended Consequences of Welfare Reform: Evidence from Birth Outcomes of Aboriginal Australians. IZA Discussion Paper No. 13543.

Dreise, Tony, Gina Milgate, Bill Perrett and Troy Meston. 2016. “Indigenous School Attendance: Creating Expectations that are 'Really High' and 'Highly Real'.” Policy Insights 1(4) 
Duflo, Esther. 2012. "Women and Empowerment and Economic Development." Journal of Economic Literature 50(4): 1051-1079.

Equality Rights Alliance. 2011. Women's Experience of Income Management in the Northern Territory. Equality Rights Alliance: Canberra.

FAHCSIA. 2008. Submission of Background Material to the Northern Territory Emergency Response Review Board. Department of Families, Housing, Community Services and Indigenous Affairs: Australian Government.

FAHCSIA. 2011. Northern Territory Emergency Response: Evaluation Report 2011. Department of Families, Housing, Community Services and Indigenous Affairs: Australian Government.

Gennetian, Lisa A., Roopa Seshadri, Nathan D. Hess, Aaron N. Winn and Robert M. Goerge, R. 2016. "Supplemental Nutrition Assistance Program (SNAP) Benefit Cycles and Student Disciplinary Infractions.” Social Service Review 90(3): 403-433.

Gentilini, Ugo. 2016. "Revisiting the "Cash Versus Food" Debate: New Evidence for an Old Puzzle?" The World Bank Research Observer 31(1): 135-167.

Goodman-Bacon, Andrew. 2018. Difference-in-Difference with Variation in Treatment Timing (Working Paper Series No. 25018). NBER Working Paper Series.

Hancock, Kristen J., Carrington C. J. Shepherd, David Lawrence and Stephen R. Zubrick. 2013. School Attendance and Educational Outcomes: Every Day Counts. Report prepared for the Department of Education, Employment and Workplace Relations.

He, Vincent, Juinn-Yih Su, John McKenzie and Stefanie Schurer. 2018. School Attendance. In Sven Silburn, Steven Guthridge, John McKenzie, Juinn-Yih Su, Vincent He and Sharon Haste (Eds.), Early Pathways to School Learning: Lessons from the NT Data Linkage Study (p. 91-109). Menzies School of Health Research.

Herbert, Jeannie, Dennis M. McInerney, Lyn Fasoli, Peter Stephenson and Lysbeth Ford. 2014. Indigenous Secondary Education in the Northern Territory: Building for the Future." The Australian Journal of Indigenous Education 43(2): 85-95.

Howard, John. 2007. To Stabilise and Protect. The Hon. John Howard MP Prime Minister of Australia Address to the Sydney Institute, Four Seasons Hotel, Sydney. Commonwealth of Australia: House of Representatives.

Hoynes, Hilary, Marianne Page and Ann Huff Stevens. 2011. "Can Targeted Transfers Improve Birth Outcomes? Evidence from the Introduction of the WIC Program.” Journal of Public Economics 95(7-8): 813-827.

Hoynes, Hilary and Diane Whitmore Schanzenbach. 2009. “Consumption Responses to In-Kind Transfers: Evidence from the Introduction of the Food Stamp Program." American Economic Journal: Applied Economics 1(4): 109-139.

Humpage, Louise. 2016. "Income Management in New Zealand and Australia: Differently Framed but Similarly Problematic for Indigenous Peoples.” Critical Social Policy 36(4): 551-571.

Hunter, Ernest and Desley Harvey. 2002. " Indigenous Suicide in Australia, New Zealand, Canada and the United States." Emergency Medicine 14(1): 14-23. 
Kremer, Michael and Alaka Holla. 2009. "Improving Education in the Developing World: What Have we Learnt from Randomized Evaluations?" Annual Review of Economics 1(1): 513542.

Kronemann, Michaela. 2007. Education is the Key: An Education Future for Indigenous Communities in the Northern Territory. Melbourne, Australia: Australian Education Union.

Lamb, David and Martin Young. 2011. “'Pushing Buttons': An Evaluation of the Effect of Aboriginal Income Management on Commercial Gambling Expenditure.” Australian Journal of Social Issues 46(2): 119-140.

Limerick, Michael. 2012. Cape York Welfare Reform Evaluation: Evaluation Overview. Department of Families, Housing, Community Services and Indigenous Affairs: Australian Government.

Lohoar, Shaun, Nick Butera and Edita Kennedy. 2014. Strengths of Australian Aboriginal Cultural Practices in Family Life and Child Rearing. Child Family Community Australia Paper No. 252014.

Mani, Anandi, Sendhil Mullainathan, Eldar Shafir and Jiaying Zhao, J. 2013. Poverty Impedes Cognitive Function. Science 341(6149): 976-980.

Marston, Greg, Philip Mendes, Shelley Bielefeld, Michelle Peterie, Zoe Staines, Z and Steven Roche. 2020. (Tech. Rep.). School of Social Science, The University of Queensland.

Martin, Karen L. 2017. Culture and Identity: LSIC Parents' Beliefs and Values and Raising Young Indigenous Children in the Twenty-first Century. In Maggie Walter, Karen L. Martin and Gawaian Bodkin-Andrews (Eds.), Indigenous Children Growing Up Strong: A Longitudinal Study of Aboriginal and Torres Strait Islander Families (pp. 79-99). London: Palgrave Macmillan.

Matheson, Don and Ned Hardie-Boys. 2011. Evaluation of the Child Health Check Initiative and the Expanding Health Service Delivery Initiative: Final Report. Report to the Department of Health and Ageing: Allen and Clarke Policy and Regulatory Specialists.

McTaggart, Robin. 1991. "Western Institutional Impediments to Australian Aboriginal Education.” Journal of Curriculum Studies 23(4): 297-325.

Melbourne Institute of Applied Economic and Social Research. 2004. Poverty Lines: Australia September Quarter 2003 (Quarterly Report No. ISSN 1448-0530). The University of Melbourne.

Memmott, Paul, Stephen Long and Linda Thomson. 2006. Indigenous Mobility in Rural and Remote Australia. Australian Housing and Urban Research Institute Final Report No. 90.

Memmott, Paul, Rachael Stacy, Catherine Chambers and Catherine Keys. 2001. Violence in Indigenous Communities. Report to Crime Prevention Branch of the Attorney-General's Department: Canberra.

Muir, Nicole Marie and Yvonne Bohr. 2014. "Contemporary Practice of Traditional Aboriginal Child Rearing: A Review." First Peoples Child and Family Review 9(1): 66-79.

Mullainathan, Sendhil and Eldar Shafir. 2013. Scarcity: Why Having So Little Means So Much. New York: Henry Holt and Company, LLC. 
Petray, Theresa. 2013. Punishing Truancy is not the Answer in Indigenous Communities. The Conversation. 17 December 2013.

Prout, Sarah. 2008. The Entangled Relationship Between Indigenous Spatiality and Government Service Delivery (No. 41/2008). Centre for Aboriginal Economic Policy Research, working paper.

Ramsey, Gregor. 2003. Report on Future Directions for Secondary Education in the Northern Territory. Charles Darwin University and NT Department of Employment, Education and Training: Report to the Northern Territory Government.

Schurer, Stefanie, Georgina Nutton, John McKenzie, Jiunn-Yih Su and Sven Silburn. 2018. “ Preschool participation, school attendance and academic achievement.” In Sven Silburn, Steve Guthridge, John McKenzie, Jiunn-Yih Su, Vincent He and Sharon Haste (Eds.), Early Pathways to School Learning: Lessons from the NT Data Linkage Study (p. 111-128). Menzies School of Health Research.

Shah, Anuj K., Sendhil Mullainathan and Eldar Shafir. 2012. "Some Consequences of Having Too Little." Science 338(6107): 682-685.

Sinha, Vandna, Nico Trocme, Barbara Fallon, Bruce MacLaurin, Elizabeth Fast, Shelley Thomas Prokop, ... Kenn Richard. 2011. Kiskisik Awasisak: Remember the Children Understanding the Overrepresentation of First Nations Children in the Child Welfare System. Ontario: Assembly of First Nations.

Southworth, Herman M. 1945. "The Economics of Public Measures to Subsidize Food Consumption." Journal of Farm Economics 27(1): 36-66.

Stanley, Janet, Adam Tomison and Julian Pocock. 2003. Child Abuse and Neglect in Indigenous Australian Communities. Australian Institute of Family Studies: NCPC Issues No. 19.

Su, Jiunn-Yih, Sven Silburn, Stefanie Schurer, Steve Guthridge, Vincent He and John McKenzie. 2018. Early Life Health and Development. In Sven Silburn, Steve Guthridge, John McKenzie, Jiunn-Yih Su, Vincent He and Sharon Haste (Eds.), Early Pathways to School Learning: Lessons from the NT Data Linkage Study (p. 2961). Menzies School of Health Research.

Taylor, Andrew and Bruce Dunn. 2010. "Conceptualising and Measuring the Mobility of Indigenous Students in the Northern Territory." The Australian Journal of Indigenous Education 39(2010): 88-97.

Trudgett, Michelle, Susan Page, Gawaian Bodkin-Andrews, Corrinne Franklin and Alison Whittaker. 2017. "Another Brick in the Wall? Parent Perceptions of School Educational Experiences of Indigenous Australian Children.” In Maggie Walter, Karen L. Martin and Gawaian Bodkin-Andrews (Eds.), Indigenous Children Growing Up Strong: A Longitudinal Study of Aboriginal and Torres Strait Islander Families (pp. 233-258). London: Palgrave Macmillan.

Walter, Maggie. 2015. "The Vexed Link Between Social Capital and Social Mobility for Aboriginal and Torres Strait Islander People.” Australian Journal of Social Issues 50(1): 69-88. 
Walter, Maggie. 2017. “Doing Indigenous Family.” In Maggie Walter, Karen L. Martin and Gawaian Bodkin-Andrews (Eds.), Indigenous Children Growing Up Strong: A Longitudinal Study of Aboriginal and Torres Strait Islander Families (pp. 123-152). London: Palgrave Macmillan.

Wild, Rex and Pat Anderson. 2007. Ampe Akelyernemane Meke Mekarle "Little Children are Sacred": Report of the Northern Territory Board of Inquiry into the Protection of Aboriginal Children from Sexual Abuse. Northern Territory Government.

Wilson, Bruce. 2013. A Share in the Future: Review of Indigenous Education in the Northern Territory. Northern Territory Government.

Yap, Mandy and Nicholas Biddle. 2010. "Gender Gaps in Indigenous Socioeconomic Outcomes: Australian Regional Comparisons and International Possibilities." The International Indigenous Policy Journal 1(2): 3.

Yu, Peter, Marcia E. Duncan and Bill Gray. 2008. Northern Territory Emergency Response: Report of the Review Board. Commonwealth of Australia. 
Figure 1: Cumulative Coverage of Income Management Across NTER Communities

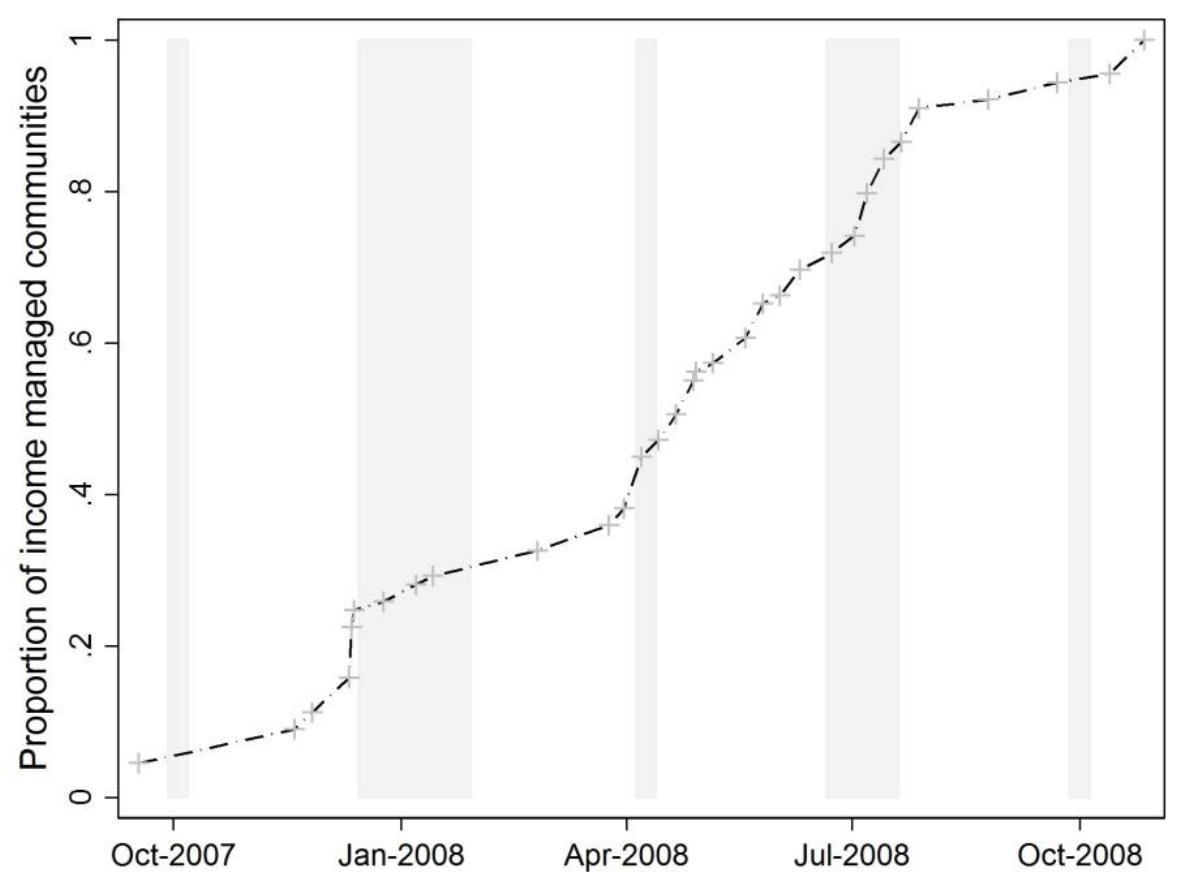

Notes: The graph shows the cumulative number of communities that have started income management on each date as a proportion of the total number of communities selected for income management. Shaded regions are school holiday periods. Crosses represent dates that income management commenced in one or more communities. For the complete rollout schedule see AIHW (2010). 
Figure 2: Map of Communities Selected for Income Management and Program Commencement Dates

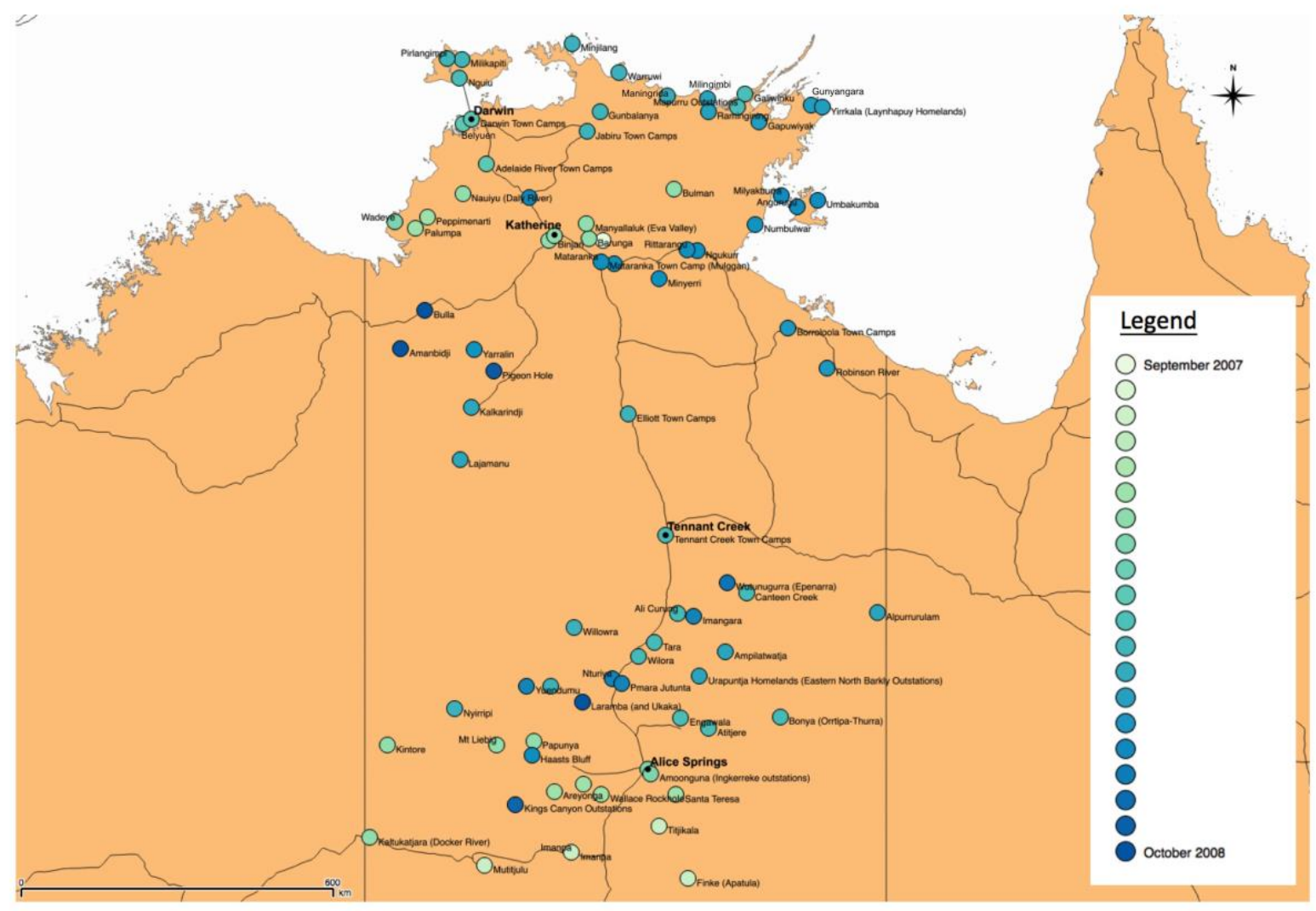

Notes: Color-coding on communities selected for income management reflects the date income management started in the relevant community as indicated in the legend. Major settlements in the Northern Territory are in boldface. People living in the municipal parts of these communities were not subject to income management (only those living in the associated town camps). Highways and arterial roads are identified by lines connecting certain communities. 
Figure 3: Budget constraints under welfare restrictions
A. Baseline
B. With underground market

Excluded goods

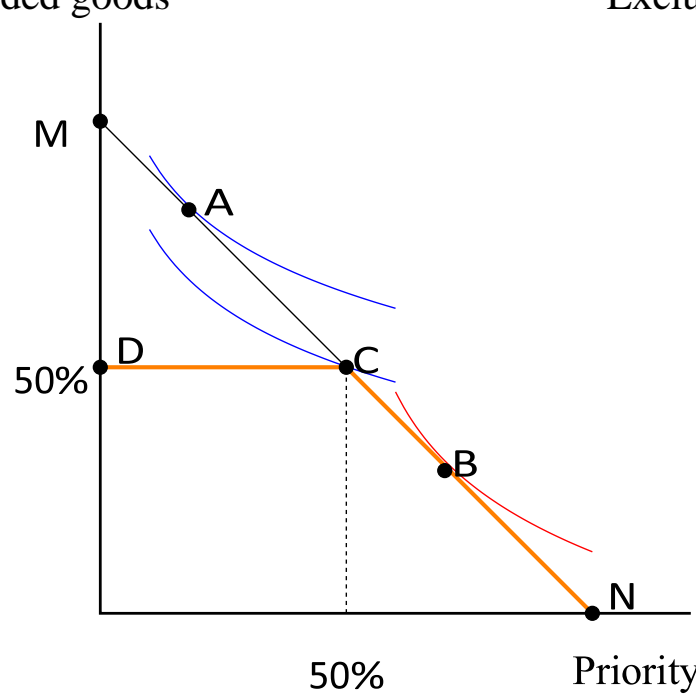

Excluded goods

M

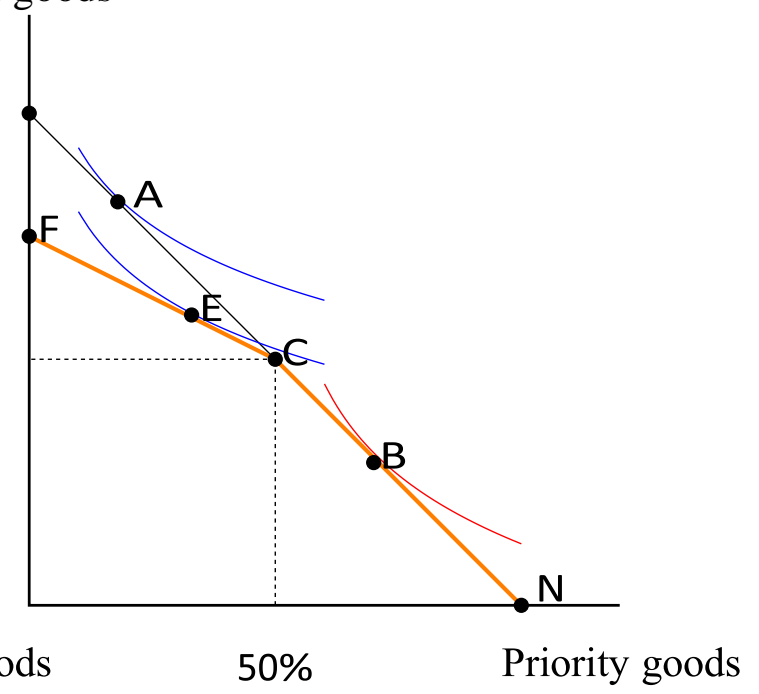

Notes: Panel A shows how the budget constraint changes when going from no welfare restrictions (MN) to 50 percent of welfare being quarantined (DCN). For a person who initially spends more than 50 percent of welfare on excluded goods (extramarginal consumer) at point A, they will consume at point $\mathrm{C}$ under the reform. In Panel B, the post-reform budget constraint is not horizontal, but is flatter once expenditure on excluded goods exceeds 50 percent, reflecting the higher underground market cost of those goods. In this case, the extramarginal consumer reduces his/her consumption of excluded goods but still allocates more than 50 percent of welfare income to them. 
Figure 4: Event Study Coefficients for School Attendance

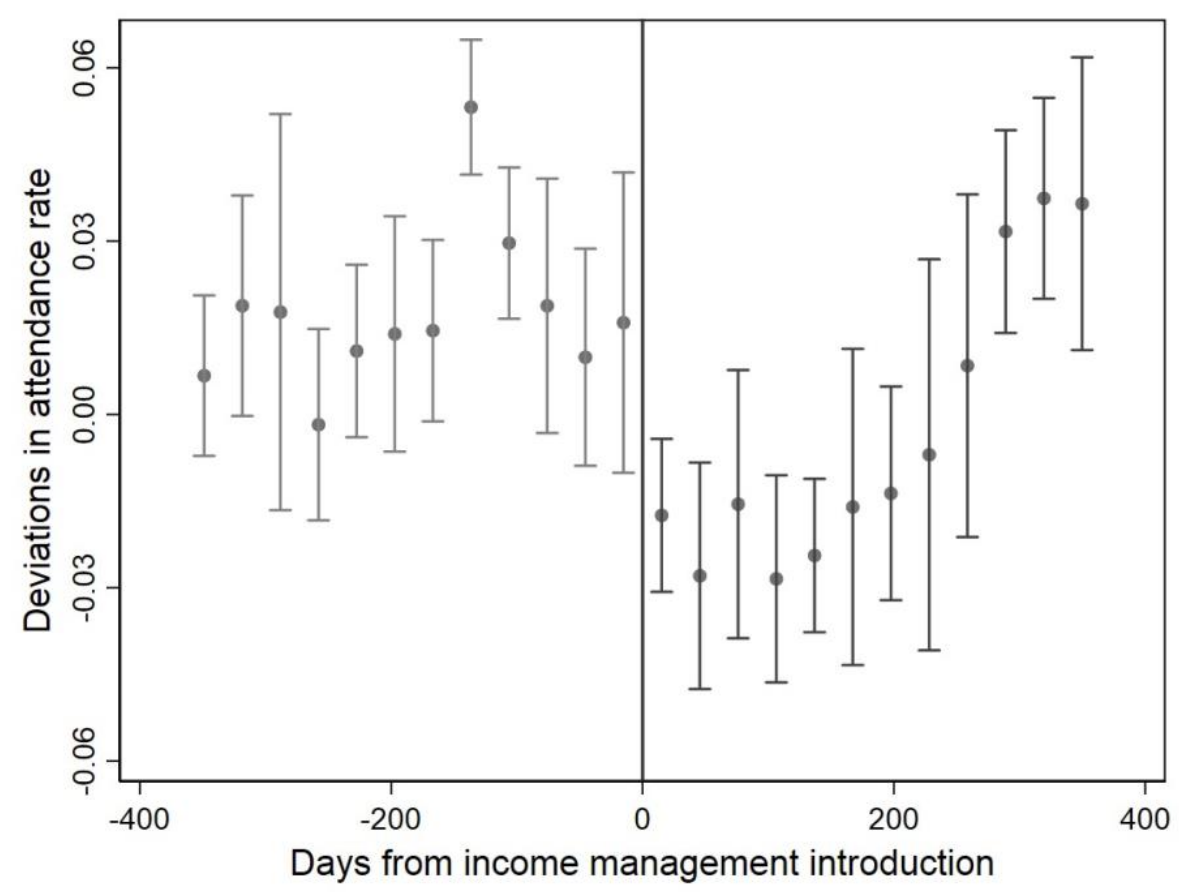

Notes: Results are based on OLS estimation of Eq. 1 using observations between \pm 365 days from the onset of income management in each community. The dependent variable is average whole-day school attendance in community $c$ on school-day $t$. The regression controls for community fixed effects and separate indicators for each event-date (i.e., time until/since income management commenced) and use weights proportional to the number of students in each community for each day. Due to school holidays and weekends, some event-dates have no observations such that the number of separate indicators is 717. Reported are estimated coefficients on the event-date dummies in Eq. 1. These are binned into 12 groups (approximately one month) each side of the implementation date. The reference period is $\tilde{\tau}_{s t}=-365$ and deviations in the attendance rate are relative to attendance on this date. Capped lines represent $95 \%$ confidence intervals. 
Figure 5: The Effect of Income Management on School Attendance: OLS estimates with TimeVarying Treatment Effects

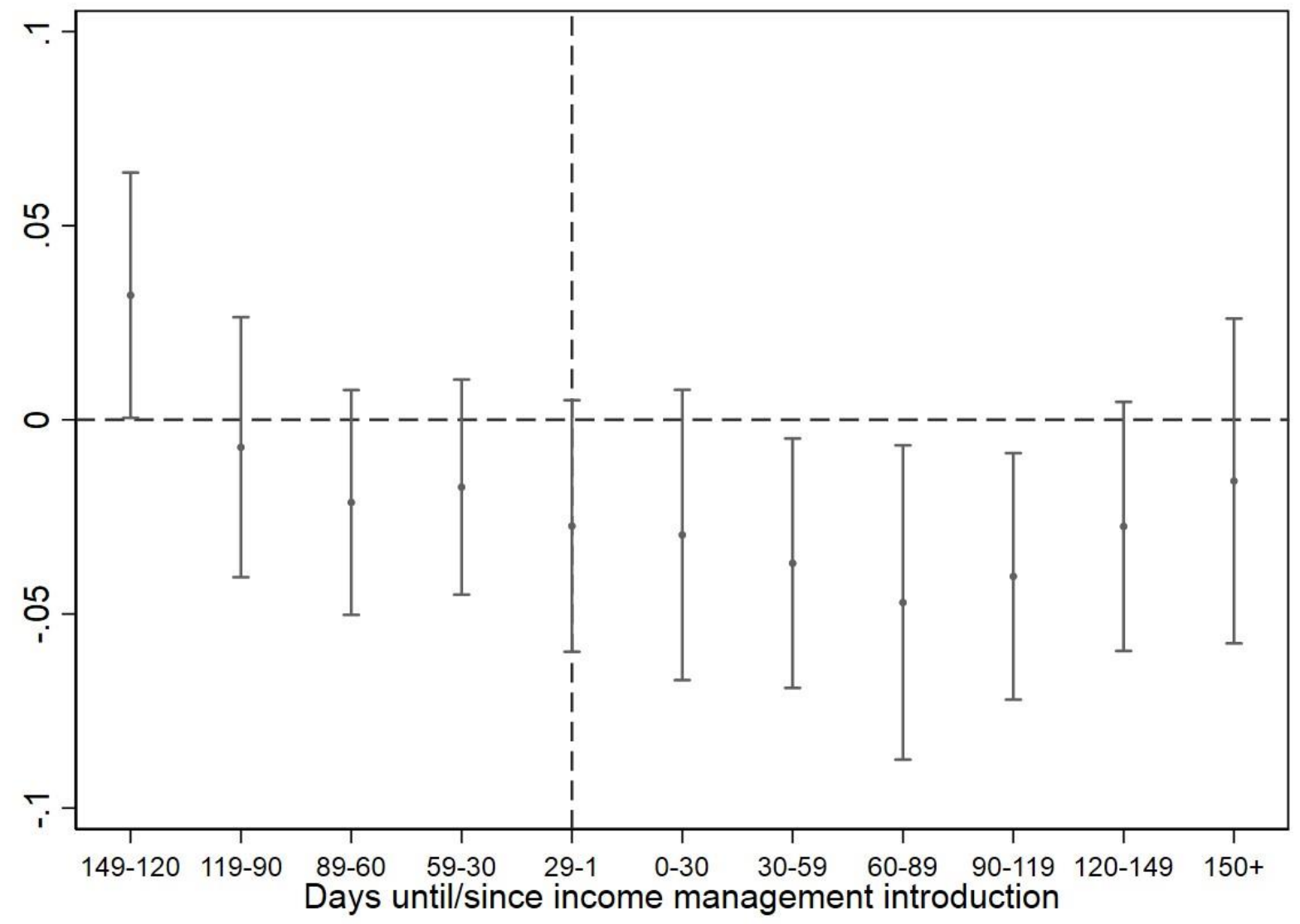

Notes: Reported are the estimated treatment effects of income management on school attendance, allowing for both pre- and post-policy dummy variables. Cluster robust (community level) standard errors are used to construct 95\% confidence intervals. The estimates are based on OLS estimation of the extended version of Eq. 3 (Model 4). The dependent variable is the average full-day school attendance at day $t$. The regression includes a full set of interactions between i) commencement group fixed effects, ii) school-term fixed effects, and iii) a linear time trend (see Model 4 of Table 4). The estimation sample is derived from an unbalanced panel of all students in grades 1-12 enrolled in the NT public education system during the period 2006-2009 (inclusive). The reference period is average school attendance from January 2006 until 5 months before income management was introduced in the community. 


\section{Figure 6: Event Study Coefficients for Number of Students Enrolled in Income-Managed Communities}

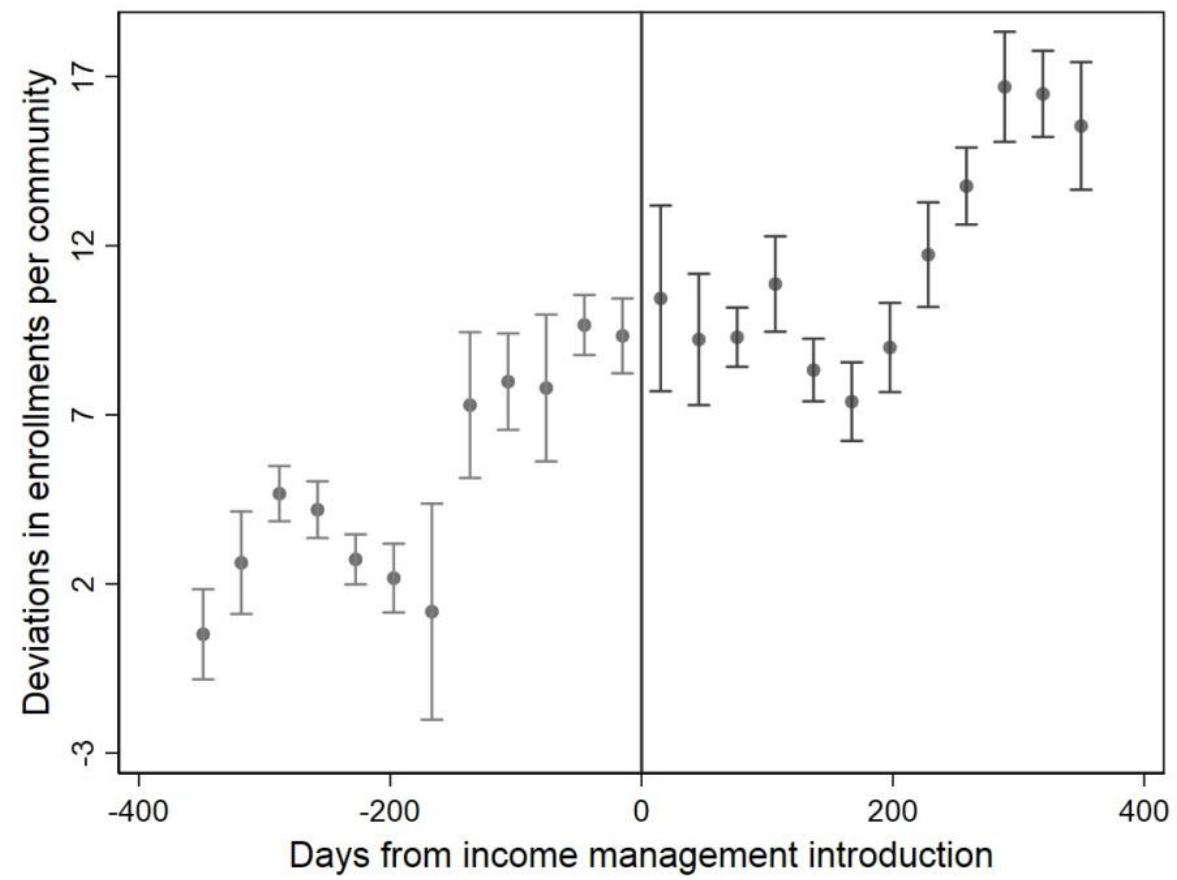

Notes: Results are based on OLS estimation of the same form as Eq. 1 using observations between \pm 365 days from the onset of income management in each community. The dependent variable is the number of students enrolled in schools located in community $c$ on school-day $t$. The regression controls for community fixed effects and separate indicators for each event-date (i.e., time until/since income management commenced) and use weights proportional to the number of students in each community for each day. Due to school holidays and weekends, some event-dates have no observations such that the number of separate indicators is 717.Reported are estimated coefficients on the eventdate dummies in Eq. 1. These are binned into 12 groups (approximately one month) each side of the implementation date. The reference period is $\tilde{\tau}_{s t}=-365$ and deviations in the attendance rate are relative to attendance on this date. Capped lines represent $95 \%$ confidence intervals. 


\section{Figure 7: Event Study Coefficients for Student Movement Into/Out of Income-Managed}

\section{Communities}
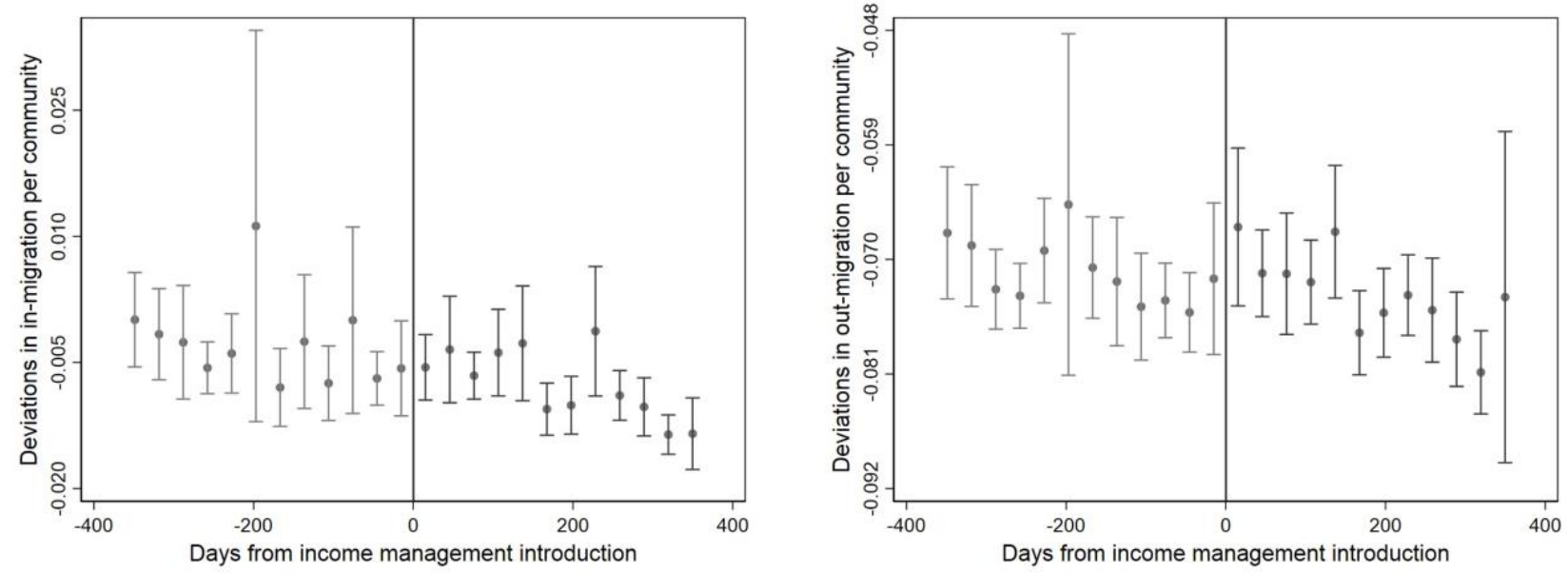

Notes: Results are based on OLS estimation of the same form as Eq. 1 using observations between \pm 365 days from the onset of income management in each community. For the left graph, the dependent variable is the total number of students moving into the community divided by the number of students already enrolled in the community on day $t$. Moves into a community include students moving from other incomemanaged communities; other non income-managed communities; or students joining the administrative dataset for the first time or after an absence of at least six months (e.g., interstate moves or moves between the private and public education sector). For the right graph, the dependent variable is the total number of students leaving the community divided by the number of students enrolled in the community on day $t$. This is the reverse of moves into a community. The regressions control for community fixed effects and separate indicators for each event-date (i.e., time until/since income management commenced) and use weights proportional to the number of students in each community for each day. Due to school holidays and weekends, some event-dates have no observations such that the number of separate indicators is 717. Reported are estimated coefficients on the event-date dummies in Eq. 1. These are binned into 12 groups (approximately one month) each side of the implementation date. The reference period is $\tilde{\tau}_{s t}=-365$ and deviations in the attendance rate are relative to attendance on this date. Capped lines represent $95 \%$ confidence intervals. 
Table 1: OLS Regression of Community Characteristics on Income Management Commencement Date

\begin{tabular}{|c|c|c|}
\hline Variable & Model 1 & Model 2 \\
\hline \multirow[t]{2}{*}{ Population/100 } & 0.803 & 2.508 \\
\hline & (14.484) & $(14.450)$ \\
\hline \multirow[t]{2}{*}{$(\text { Population/100) })^{2}$} & -0.287 & -0.349 \\
\hline & $(0.681)$ & $(0.676)$ \\
\hline \multirow[t]{2}{*}{ Percentage male } & 2.996 & 0.372 \\
\hline & $(5.541)$ & $(5.194)$ \\
\hline \multirow[t]{2}{*}{ Median age } & 7.159 & 8.040 \\
\hline & (8.126) & (8.028) \\
\hline \multirow[t]{2}{*}{ Percentage English only language spoken at home } & 0.811 & 0.861 \\
\hline & $(0.615)$ & $(0.587)$ \\
\hline \multirow[t]{2}{*}{ Labor force participation rate } & -0.150 & -0.045 \\
\hline & $(1.005)$ & $(1.027)$ \\
\hline \multirow[t]{2}{*}{ Employment rate } & 0.228 & 0.230 \\
\hline & $(0.703)$ & $(0.701)$ \\
\hline \multirow[t]{2}{*}{ Median weekly personal income } & 0.168 & 0.166 \\
\hline & $(0.248)$ & $(0.230)$ \\
\hline \multirow[t]{2}{*}{ Average people per household } & $25.728^{*}$ & $25.512^{*}$ \\
\hline & $(13.636)$ & $(13.813)$ \\
\hline \multicolumn{2}{|l|}{ Demographics miss } & $\begin{array}{c}366.269 \\
(260.483)\end{array}$ \\
\hline $\mathrm{N}$ & 55 & 64 \\
\hline $\mathrm{R}_{2}$ & 0.090 & 0.077 \\
\hline
\end{tabular}

Notes: Robust standard errors in parentheses. The dependent variable is the date income management was implemented in the community, with each day equal to one unit. Data on community characteristics are from the 2006 Australian Census using the geospatial unit 'Indigenous Local Area'. For the 14 communities for which we have no data, a suitably granular spatial unit could not be identified in the Census. Estimates are obtained by OLS. * is statistical significance at the $10 \%$ level. 
Table 2: Sample Statistics for School Attendance Data: Communities Selected for Income Management

\begin{tabular}{lccccc}
\hline & \multicolumn{5}{c}{ Primary students $^{a}$} \\
\cline { 2 - 6 } & 2006 & 2007 & 2008 & 2009 & All years \\
\hline Attendance rate (\%) $^{\mathrm{b}}$ & 63.17 & 64.00 & 62.69 & 64.95 & 63.73 \\
Moved (\%) $^{\mathrm{c}}$ & 40.50 & 38.55 & 40.14 & 39.42 & 58.12 \\
\hline No. Students & 4682 & 4877 & 5007 & 5236 & 8491 \\
\hline & \multicolumn{5}{c}{ Secondary students } \\
\cline { 2 - 6 } & 2006 & 2007 & 2008 & 2009 & All years \\
\hline Attendance rate (\%) & 63.16 & 60.77 & 56.92 & 56.16 & 57.91 \\
Moved (\%) & 49.21 & 50.69 & 51.69 & 53.95 & 67.22 \\
\hline N Students & 378 & 1014 & 1658 & 2037 & 2660 \\
\hline
\end{tabular}

Notes: Data are from the NT Department of Education administrative records and the reported statistics are based on the authors' calculations. The sample includes students born from 1994 enrolled in schools administered by the NT Department of Education operating in communities selected for income management. ${ }^{\text {a }}$ Primary students are those enrolled in grades 1-6. Secondary students are in grades 7-12. ${ }^{\mathrm{b}}$ The attendance rate is the sum of student-day observations where the student attended school the whole day divided by the number of student-day observations where the student was expected to attend school. ${ }^{\mathrm{c}}$ Moved is an indicator variable for if at any time during the period the student changed his/her enrollment to a school into a different community (intracommunity school changes are excluded) or left/joined the NT administrative dataset (which include interstate moves or moves between the private/public sector). Students are counted as having left if they exit the dataset for at least six months. Students are counted as having joined if they first enter the dataset or return to the dataset after an absence of at least six months. Students who join the sample in grade 1 or exit the sample in grades 11 or 12 are not included in this calculation. 
Table 3: Characteristics of Communities Selected for Income Management Compared to the Australian General Population

\begin{tabular}{lccccc}
\hline & \multirow{2}{*}{ Aus. Pop. } & \multicolumn{4}{c}{ Sample } \\
\cline { 2 - 6 } \cline { 3 - 6 } Variable & Mean & Mean & St. Dev. & Min & Max \\
\hline Population & - & 428.27 & 361.04 & 83 & 1904 \\
Male (\%) & 49.4 & 48.57 & 3.28 & 40.87 & 56.52 \\
Median age (years) & 37 & 22.09 & 2.16 & 18 & 27 \\
English only language spoken at home (\%) & 78.5 & 17.23 & 22.60 & 0 & 94.38 \\
Labor force participation rate (\%) & 64.6 & 37.78 & 16.23 & 6.90 & 83.50 \\
Employment rate (\%) & 94.8 & 86.00 & 15.91 & 9.22 & 100 \\
Median weekly personal income (\$AUD) & 466 & 209.82 & 39.93 & 148 & 466 \\
Average people per household & 2.6 & 6.08 & 1.43 & 3.3 & 9.6 \\
\hline
\end{tabular}

Notes: Data are from the 2006 Australian Census. For the sample characteristics, $\mathrm{N}=64$ in the case of population and percentage males. $\mathrm{N}=55$ for all other variables. Community data are for the Indigenous Local Area for that community. For the missing observations, a suitably granular spatial unit could not be identified in the Census data. 
Table 4: The Effect of Income Management on School Attendance: OLS Regression Results
(1)
(2)
(3)
(4)

\section{Panel A: Single treatment identifier}

\begin{tabular}{|c|c|c|c|c|}
\hline Treatment & $\begin{array}{l}-0.015 \\
(0.010)\end{array}$ & $\begin{array}{l}-0.022^{*} \\
(0.013)\end{array}$ & $\begin{array}{l}-0.020^{*} \\
(0.010)\end{array}$ & $\begin{array}{l}-0.019^{*} \\
(0.010)\end{array}$ \\
\hline \multicolumn{5}{|c|}{ Panel B: Treatment effect by time since income management commenced } \\
\hline \multirow[t]{2}{*}{$<30$ days ago } & $-0.037^{* *}$ & -0.012 & -0.021 & -0.022 \\
\hline & $(0.016)$ & $(0.015)$ & $(0.016)$ & $(0.016)$ \\
\hline \multirow[t]{2}{*}{ 30-59 days ago } & $-0.034^{* *}$ & -0.023 & $-0.032^{* *}$ & $-0.031^{* *}$ \\
\hline & $(0.016)$ & $(0.014)$ & $(0.012)$ & $(0.013)$ \\
\hline \multirow[t]{2}{*}{$60-89$ days ago } & $-0.052^{* * *}$ & $-0.033^{* *}$ & $-0.042^{* * *}$ & $-0.041^{* *}$ \\
\hline & $(0.016)$ & $(0.016)$ & $(0.016)$ & $(0.016)$ \\
\hline \multirow[t]{2}{*}{ 90-119 days ago } & $-0.054^{* * *}$ & $-0.033^{*}$ & $-0.035^{* * *}$ & $-0.034^{* * *}$ \\
\hline & $(0.017)$ & $(0.018)$ & $(0.013)$ & $(0.012)$ \\
\hline \multirow[t]{2}{*}{ 120-149 days ago } & & -0.028 & $-0.023^{*}$ & -0.021 \\
\hline & $(0.015)$ & $(0.020)$ & $(0.013)$ & $(0.013)$ \\
\hline \multirow[t]{2}{*}{$150+$ days ago } & -0.006 & -0.006 & -0.005 & -0.006 \\
\hline & $(0.011)$ & $(0.016)$ & $(0.014)$ & $(0.015)$ \\
\hline Community FE & & $\mathrm{Y}$ & $\mathrm{Y}$ & $\mathrm{Y}$ \\
\hline Time FE & & Y & & \\
\hline Time trend & & & $\mathrm{Y}$ & $\mathrm{Y}$ \\
\hline School-Term FE & & & $\mathrm{Y}$ & $\mathrm{Y}$ \\
\hline C. group $\times$ Term & & & $\mathrm{Y}$ & Y \\
\hline C. group $\times$ Time trend & & & & $\mathrm{Y}$ \\
\hline Time trend $\times$ Term & & & & $\mathrm{Y}$ \\
\hline C. group $\times$ Term $\times$ Time trend & & & & $\mathrm{Y}$ \\
\hline Day of the week FE & & $\mathrm{Y}$ & $\mathrm{Y}$ & $\mathrm{Y}$ \\
\hline
\end{tabular}




\begin{tabular}{lcccc}
\hline $\mathrm{N}$ & 55902 & 55902 & 55902 & 55902 \\
$\mathrm{R} 2$ & 0.005 & 0.529 & 0.517 & 0.535
\end{tabular}

Notes: The dependent variable is the average full-day school attendance at day $t$ in community $c$. The estimation sample is derived from an unbalanced panel of all students in grades 1-12 enrolled in the NT public education system during the period 2006-2009 (inclusive). The full set of available controls include community fixed effects, time fixed effects (day level), a linear time trend, day of the week fixed effects (Monday-Friday), school-term fixed effects and average grade level for the community. There are four school terms per year; in 2007 the school terms were as follows: term 1 - 29 January-5 April; term 2 - 16 April-22 June; term 3 - 23 July-28 September; and term $4-8$ October-14 December. These dates are similar for other years. Panel A and Panel B are the results of separate OLS regressions. All regressions use weights proportional to the number of students in each community for each day. Cluster robust (community level) standard errors reported in parentheses. Significance level: ${ }^{*} p<.10,{ }^{* *} p<0.05$, ${ }^{* * *} p<0.01$. 
Table 5: The Effect of Income Management on School Attendance by Gender, School Level and School Attachment: OLS Regression Results



Notes: All results are based on OLS estimation of the extended version of Eq. 3. The dependent variable is the average full-day schoolattendance at day $t$ in community $c$, for the relevant sub-sample of students. The regression includes a full set of interactions between i) commencement group fixed effects, ii) school-term fixed effects, and iii) a linear time trend (see Model 4 of Table 4). The estimationsample is derived from an unbalanced panel of all students in grades 1-12 enrolled in the NT public education system during the pe- riod 2006-2009 (inclusive). $\quad{ }^{\text {a }}$ High and low attendance students: The latent individual propensity to attend school for each student is predicted by backing-out the individual fixed effects after estimating Model 4 (including interactions with time since policy onset) by OLS regression using all available time series data on school attendance for each student. Low attendance students have a latent propensity smaller than the median; high attendance students have a latent propensity equal or greater than the median. Panel A and Panel B are the results of separate OLS regressions. All regressions use weights proportional to the number of students (for the particu-lar sub-group) in each community for each day. Cluster robust (community level) standard errors reported in parentheses. Significance level: ${ }^{*} p<.10,{ }^{* *} p<0.05,{ }^{* * *} p<$ 0.01 . 
Table 6: Number of Communities (Proportion of Total Selected) to Receive Major NTER Measures July 2007-July 2008

\begin{tabular}{lllll}
\hline Measure & Jul-Sep 2007 & Oct-Dec 2007 & Jan-Mar 2008 & $\begin{array}{l}\text { Apr-Jul } \\
2008\end{array}$ \\
\hline \multicolumn{2}{l}{ Welfare reform and employment } & & \\
\hline Income management & $4(4.8)$ & $23(27.7)$ & $33(39.7)$ & $78(94.0)$ \\
Store license & $2(3.7)$ & $8(14.8)$ & $18(33.3)$ & $54(100.0)$ \\
RAEs lifted & $15(23.0)$ & $65(100.0)$ & $65(100.0)$ & $65(100.0)$ \\
CDEP transition & $3(3.6)$ & $30(36.1)$ & $30(36.1)$ & $30(32.5)$ \\
CEBs & $25(35.6)$ & $38(53.4)$ & $54(76.7)$ & $69(83.1)$ \\
\hline
\end{tabular}

\section{Education and child health}

\begin{tabular}{lllll}
\hline Child health checks & $22(26.5)$ & $48(57.8)$ & $69(83.1)$ & $81(97.6)$ \\
School nutrition & $3(4.4)$ & $7(9.6)$ & $25(34.2)$ & $68(93.2)$ \\
Accelerated literacy & $0(0.0)$ & $0(0.0)$ & $0(0.0)$ & $30(81.1)$ \\
Quality teacher package & $0(0.0)$ & $0(0.0)$ & $0(0.0)$ & $34(85.0)$ \\
\hline
\end{tabular}

Law and order

\begin{tabular}{lllll}
\hline Banning alcohol & $73(88.0)$ & $83(100.0)$ & $83(100.0)$ & $83(100.0)$ \\
Banning pornography & $73(88.0)$ & $83(100.0)$ & $83(100.0)$ & $83(100.0)$ \\
Night patrols & $0(0.0)$ & $0(0.0)$ & $1(2.2)$ & $14(39.1)$ \\
Extra police & $6(8.2)$ & $12(16.4)$ & $16(21.9)$ & $17(23.3)$ \\
THEMIS police station & $6(8.2)$ & $12(16.4)$ & $16(21.9)$ & $17(23.3)$ \\
\hline Family support & & & $0(0.0)$ & $10(13.7)$ \\
\hline Safe house & $0(0.0)$ & $0(0.0)$ & $0(0.0)$ & $12(14.4)$ \\
RAFCW & $0(0.0)$ & $0(0.0)$ & $0(0.0)$ & $12(14.4)$ \\
Child special services & $0(0.0)$ & $0(0.0)$ & & $68(100.0)$ \\
\hline Housing and land & & & $65(95.6)$ & $72(98.6)$ \\
\hline Leases & $27(39.7)$ & $27(39.7)$ & $0(0.0)$ & $81(100.0)$ \\
All CCU works completed & $0(0.0)$ & $0(0.0)$ & $81(100.0)$ \\
\hline $\begin{array}{l}\text { Governance } \\
\text { GBMs }\end{array}$ & $12(14.8)$ & $67(82.7)$ & \\
\hline $\begin{array}{l}\text { Source: Yu et al. (2008). Figures for each quarter are the cumulative number of communities that received the measure by the end of that } \\
\text { quarter. The percentage of communities to have received the measure relative to the target number of communities is in parentheses. For } \\
\text { details on each measure see Table A1. }\end{array}$ & & &
\end{tabular}


Table 7: Regression Estimates for the Effect of Income Management on Family Disruption

\begin{tabular}{|c|c|c|c|c|}
\hline & Humbugging & Alcohol use & Arguing & $\begin{array}{c}\text { Money } \\
\text { concerns }\end{array}$ \\
\hline \multirow[t]{2}{*}{ Treatment } & 0.030 & 0.066 & -0.048 & -0.059 \\
\hline & $(0.081)$ & $(0.090)$ & $(0.068)$ & $(0.086)$ \\
\hline \multirow[t]{2}{*}{ Wave 2} & 0.024 & $-0.062^{* * *}$ & -0.010 & -0.009 \\
\hline & $(0.018)$ & $(0.017)$ & $(0.017)$ & $(0.019)$ \\
\hline \multirow[t]{2}{*}{ Treatment $\times$ Wave $2\left(\widehat{\beta}_{3}\right)$} & $0.201^{*}$ & 0.040 & 0.067 & 0.150 \\
\hline & (0.114) & (0.119) & $(0.085)$ & $(0.098)$ \\
\hline \multirow[t]{2}{*}{ Continuous } & $0.261^{* * *}$ & $0.188^{* *}$ & $0.143^{*}$ & -0.075 \\
\hline & $(0.085)$ & $(0.084)$ & $(0.080)$ & $(0.073)$ \\
\hline \multirow[t]{2}{*}{ Continuous $\times$ Wave $2\left(\hat{\beta}_{5}\right)$} & -0.091 & 0.050 & -0.134 & 0.063 \\
\hline & $(0.093)$ & $(0.112)$ & $(0.090)$ & $(0.095)$ \\
\hline \multirow[t]{2}{*}{ Constant } & $0.212^{* * *}$ & $0.256^{* * *}$ & $0.191^{* * *}$ & $0.318^{* * *}$ \\
\hline & $(0.014)$ & $(0.015)$ & $(0.014)$ & $(0.016)$ \\
\hline \multirow[t]{2}{*}{$\widehat{\beta} D D D$} & $0.292^{* *}$ & -0.009 & $0.201^{*}$ & 0.087 \\
\hline & $(0.145)$ & $(0.161)$ & $(0.122)$ & $(0.134)$ \\
\hline $\mathrm{N}$ & 1740 & 1726 & 1726 & 1737 \\
\hline
\end{tabular}

Notes: Data are from the 2008 and 2009 waves of LSIC. Dependent variables are all indicator variables for the following. Humbugging: In the last year have you or your family been humbugged (harassed for money)? Alcohol use: In the last year have you or a close family member had an alcohol or drug problem? Arguing: In the last year has (STUDY CHILD) or any other child of yours been involved in or upset by family arguments? Money concerns: In the last year has your family had serious worries about money? Treatment is an indicator for if the individual goes on to income management in wave 2. Continuous is an indicator for those on income management in both waves. Wave 2 is an indicator for the second wave of LSIC. $\widehat{\beta}_{D D D}=\widehat{\beta}_{3}-\widehat{\beta}_{5}$. Estimates are obtained by OLS.

Cluster robust (individual level) standard errors reported in parentheses. Significance level: ${ }^{*} p<.10,{ }^{* *} p<0.05,{ }^{* * *} p<0.01$. 
1 'Aboriginal and Torres Strait Islander' is the preferred term for the Indigenous peoples of Australia. We will refer them simply as 'Aboriginal'.

${ }^{2}$ We analyze the rollout of income management in 2007. It was in place until 2010 when a revised policy, New Income Management (NIM), became universal for the entire Northern Territory (Bray et al., 2014).

3 The Commonwealth Government committed to a series of infrastructure and curriculum initiatives to cater for the anticipated increased demand for education. These were intended to be carried out mainly through a Memorandum of Understanding between the Commonwealth and Northern Territory Governments which was signed on September 16, 2007. The legislation allowed for up to 100 percent of welfare payments to be quarantined if children were not attending school; however, this was never implemented (Yu et al., 2008, p. 29).

${ }^{4}$ Mean gross income for NT households deriving their income mainly from government benefits was \$419AUD (vs. \$1401AUD for all household zds) (authors' calculations, 2003-04 Household Expenditure Survey data). The national poverty line in September 2003 for a household with one dependent child and the head of the household not working was \$460.96AUD (including housing) (Melbourne Institute of Applied Economic and Social Research, 2004).

${ }^{5}$ Centrelink is the Australian Government agency responsible for administering all transfer payments.

${ }^{6}$ EFTPOS (electronic funds transfer at the point of sale) is Australia's most widely used payment system handling 70 percent of debit card transactions. See www.mobiletransaction.org/australianeftpos-system/.

${ }^{7}$ Town camps are small Aboriginal settlements located within the boundaries of major towns such as Darwin, Tennant Creek and Alice Springs. 
${ }^{8}$ We regress the date at which income management began on a set of community level characteristics. See for example Hoynes and Schanzenbach (2009), Hoynes et al. (2011), Bailey (2012) and Bailey and Goodman-Bacon (2015) who adopt the same approach when relying on program timing for identification.

${ }^{9}$ We have evidence that our missing data are related to rollout timing. The correlation coefficient between implementation date and an indicator for missing data is only $0.014(\mathrm{p}=0.902)$. Communities with missing data comprise only 6.6 percent of students in our main sample. Dropping these communities does not materially affect our results.

${ }^{10} \mathrm{We}$ are aware of only one other scheme internationally that involves involuntary income quarantining. Since 2012, New Zealanders aged 16-19 have been subject to an income management scheme similar to that studied here. While New Zealand's scheme does not directly target its Indigenous population, it does disproportionately affect it (Humpage, 2016). We are not aware of any impact evaluation of income management in New Zealand.

${ }^{11}$ Social Security and Other Legislation Amendment (Welfare Payment Reform) Act 2007 No. 130, 2007 123TB Objects, Section (a). The legislation (123TB Objects, Section (c)) further stated that it should ensure that "the amount set aside is directed to meeting the priority needs of (i) the recipient of the welfare payment; and (ii) the recipient's partner; and (iii) the recipient's children; and (iv) any other dependants of the recipient."

${ }^{12}$ See Southworth (1945) and Doyle et al. (2020) for similar diagrams depicting the way public subsidies affect post-war consumption of food and the impact of welfare restrictions, respectively. ${ }^{13}$ Results provided upon request. The NT and Australian Capital Territory are combined in the HES micro-dataset, and we do not observe whether households are living in urban centres. 
${ }^{14}$ All NT Government schools are required to provide daily records of student attendance through a centralized electronic database - the Student Administration and Management System. Upon initial enrollment, each student is given a unique identifying number, which allows us to track individual students across time and schools. We do not have data for private schools which operate in six of the communities in our sample.

${ }^{15}$ We matched communities to school names by looking up school addresses in the NT Schools Directory, or, in some cases, using the school's own website. We were able to match 130 schools in our data belonging to 78 separate communities. In most communities there is one major school; 61 communities have a single school only. Forty-seven of our schools are thomeland learning centers', which are government-funded education facilities operating in very remote areas without the staffing or infrastructure requirements of a regular school. They have only a few enrollments at any time and comprise a small fraction of student-day observations in our sample.

${ }^{16}$ Many Aboriginal languages are spoken across the Northern Territory. English is often the second language.

${ }^{17}$ For example, if income management is introduced on a Monday for community $c$, then there is no observation for $\tilde{\tau}_{c t}=-1$ for that community as no student is expected to attend school on a Sunday.

18 The commencement group variables are indicators for clusters of communities that commenced income management on the same day. We interact school term, and latter linear time trends, with commencement group rather than community since this improves precision but the choice should not directly affect the estimated coefficients (indeed, estimates using community dummies are nearly identical). We thank an anonymous reviewer for this suggestion. 
${ }^{19}$ Another common approach for testing the exogeneity of policy timing is to estimate a "pseudo policy effect'. We are constrained by the fact that our data only go back to 2005 . However, we calculated pseudo policy effects by assuming that income management was introduced two years before its actual implementation and re-estimating all models over the period 2005-2007 (inclusive). Results from this exercise reveal no consistent evidence of a pseudo policy effect (see Table A2), which supports our identification strategy.

${ }^{20}$ Since time varying treatment effects may be confounded with post-treatment trends, we also estimate a version of Model 4 where time trends are only estimated for observations in the preincome management period and are then 'netted-out' of average attendance. These estimates are very similar to those reported in column 4 of Table 4 (see Appendix Table A3).

${ }^{21}$ In addition to the additional controls, one reason Figures 4 and 5 differ is because Figure 4 averages across eventday coefficients which effectively weights each event-day equally, whereas in Figure 5 each day is effectively weighted by the number of observations on that day.

22 This stems from the fact that the estimator is actually a weighted sum of many two-group DD estimates, with weights that can be negative, and where treated units are sometimes controls for units that change treatment status. Solutions typically involve some element of narrowing the treatment period and using only untreated units as controls

${ }^{23}$ As in Figure 5, the results in Figure A2 indicate the policy may have had some adverse impact in the month preceding commencement. Compared to 30-59 days before commencement, we estimate that students were $4.3 \mathrm{ppts}(\mathrm{p}=0.043)$ less likely to attend 30-59 days after the policy began and 4.5 ppts ( $\mathrm{p}=0.052$ after 60-89 days, which is similar to our estimates in Table 4 . When we specify a single treatment effect for the whole 150 days we estimate a reduction of 3.2 ppts $(\mathrm{p}=0.091)$ across this period, which is almost identical to our main results. 
24 The latent individual propensity to attend school for each student is predicted by backing-out the individual fixed effects after estimating Model 4 (including interactions with time since policy onset) using OLS regression and including all available observations on school attendance for each student. Because we have daily school data, the expected bias in the estimation of the individual fixed effects is likely to be small $(\bar{T}=542)$. A second source of bias comes from the fact that heterogeneity in the treatment effect by attendance propensity is not controlled for in the estimation used to obtain the individual fixed effects. However, since the average treatment effect is small relative to the average attendance propensity ( $1.8 \mathrm{ppts}$ relative to 62.7 percent), this bias is also likely to be small.

${ }^{25}$ Alcohol related laws came into effect on 18 August 2007 and alcohol offences on 15 September 2007 (Central Land Council, 2008).

${ }^{26} \mathrm{School}$ meal programs in poor countries have proven effective in raising school attendance. See Kremer and Holla (2009) for an overview. Yu et al. (2008) find no empirical evidence of improved attendance when comparing a sample of schools that were early as opposed to late recipients of the school nutrition program.

${ }^{27}$ We do not observe enrollment rates because we do not observe the number of children in the community.

28 This also contributes to the variability in Figure 6, along with the fact that not every school represented in each event-day coefficient due to school holidays and weekends.

${ }^{29}$ In theory, income management may have increased geographic mobility to avoid the policy. In practice, however, this is unlikely to be empirically important as virtually all Aboriginal communities were ultimately subject to income management. In order to avoid the policy, a community member would have had to leave Aboriginal land altogether. Moreover, once income- 
managed, a welfare recipient would still be subject to income management even if she moved away.

${ }^{30}$ Personal communication with Olga Havnen, NT Coordinator General for Remote Service Delivery during the Northern Territory Emergency Response (November 22, 2017). Central Land Council (2008) reports disruption effects in six selected communities including lack of access to funds, missing transfers, and long waiting times at Centrelink to collect store cards.

${ }^{31}$ Unfortunately, data on the shortfalls of benefit payments per community are not available to rigorously test for the extent of financial disruption.

32 The Basics Card was introduced on September 8, 2008 and was completely rolled out to all income-managed clients by December 15, 2008 three months later. Information regarding the rollout schedule for the Basics Card is not available. This means that we cannot test whether the Basics Card had benefits by reducing transaction costs.

${ }^{33}$ More generally, Mullainathan and Shafir (2013) argue that it is the tax on cognitive "bandwidth" - generated by a lack of income - which explains the link between disadvantage and ineffective parenting.

${ }^{34}$ Our DDD estimates capture the difference in two separate difference-in-difference (DD) estimates that use those never on income management as a reference group. The first DD estimate is for those going on to income management; the second DD estimate is for those continuously on income management. Taking the difference between these estimates captures differential time trends between the two control groups, those never on income management and those always on income management

${ }^{35}$ Figures on the cost of income management are reported in Buckmaster et al. (2012) based on budget papers available at www.budget.gov.au. The cost per person is calculated using the total 
number of persons who had been subjected to income management as of 31 March $2009(21,763)$ (reported in AIHW, 2010). 